\title{
Photoisomerization and mesophase formation in
}

\author{
azo-ionic liquids
}

Olivier Renier ${ }^{a}$, Guillaume Bousrez ${ }^{a}$, Kathrin Stappert ${ }^{b}$, Magdalena Wilk-Kozubea $^{c}$, Brando Adranno $^{a}$, Hanwen Pei ${ }^{a}$, Eike T. Spielberg ${ }^{b}$, Volodymyr Smetana ${ }^{a}$ and Anja-Verena Mudring*a,b

${ }^{a}$ Department of Materials and Environmental Chemistry, Stockholm University, Svante Arrhenius väg 16C, 10691 Stockholm, Sweden. anja-verena.mudring@mmk.su.se

${ }^{b}$ former address: AnorganischeChemie III - Materials Engineering and Characterization, Fakultät für Chemie and Biochemie, Ruhr-Universität Bochum, 44780, Bochum, Germany.

\section{$\underline{\text { Content }}$}

I. ${ }^{1} \mathrm{H}$ and ${ }^{13} \mathrm{C}$ NMR spectra for compounds $1 \mathbf{b}-5 \mathbf{b}, 1 \mathrm{c}-5 \mathrm{c}, \mathbf{1 - 6}$ S2

II. Infra-red spectra for compounds 1b-5b, 1c-5c, 1-6 S13

$\begin{array}{ll}\text { III. Thermogravimetric analysis for compounds 1-5 S21 } & \text { Th }\end{array}$

IV. DFT Calculations for compounds 1-5 S24

I. $\quad \underline{\mathrm{H} \text { and }{ }^{13} \mathrm{C} \text { NMR spectra }}$ 


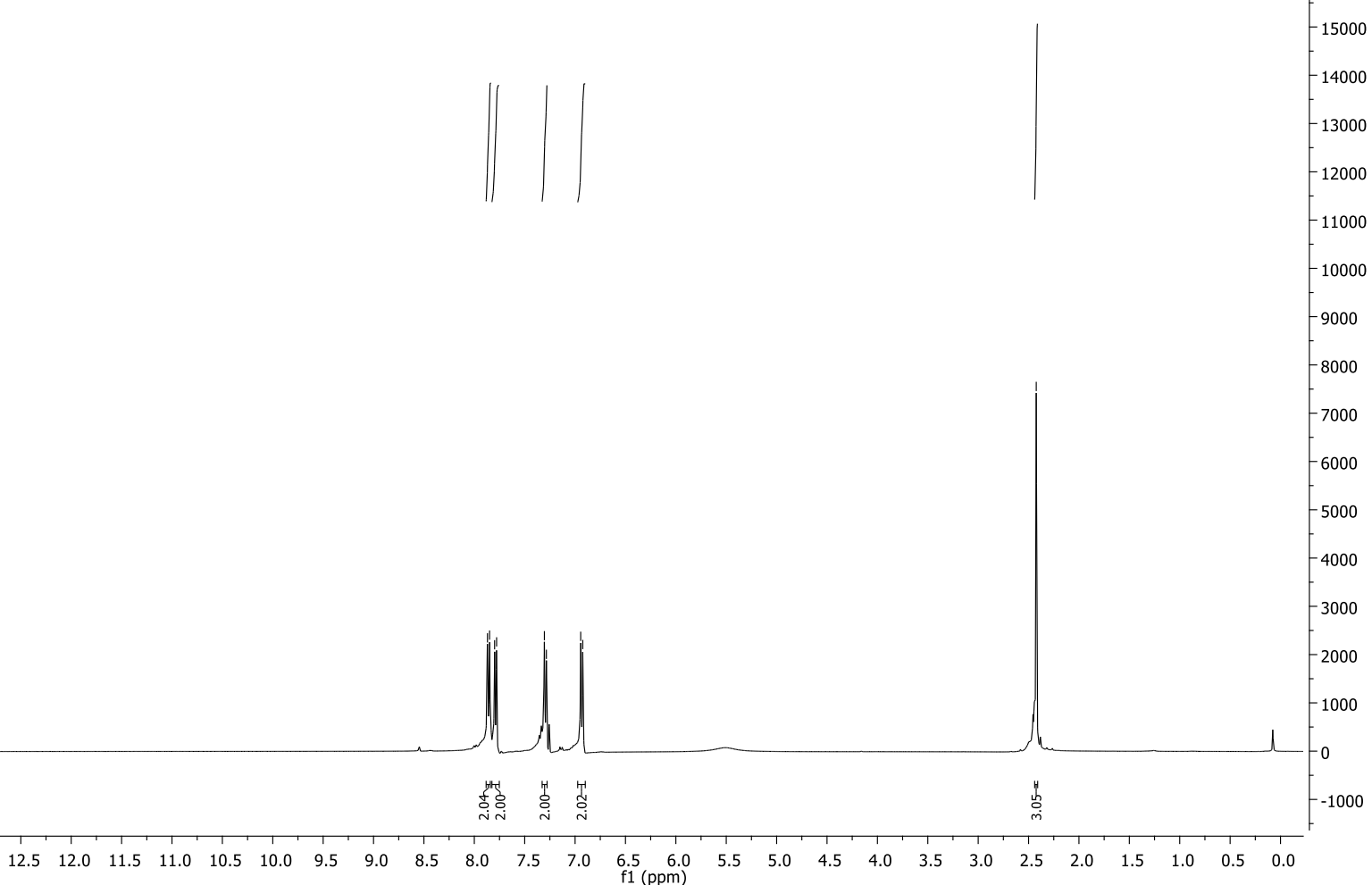

Figure S1: ${ }^{1} \mathrm{H}-\mathrm{NMR}$ spectrum (400 MHz, DMSO) of compound $\mathbf{1 b}$.

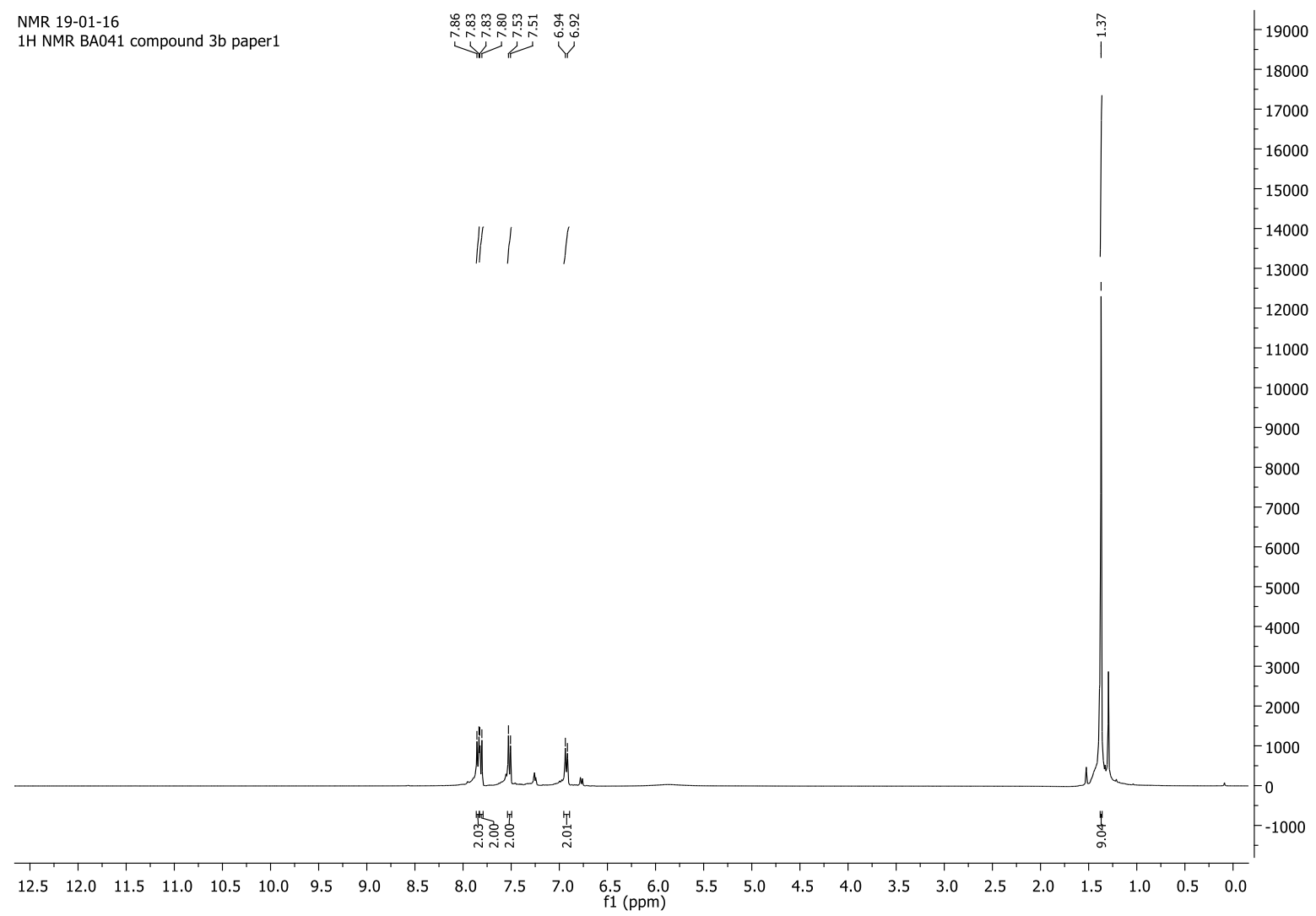

Figure S2: ${ }^{1} \mathrm{H}-\mathrm{NMR}$ spectrum (400 MHz, DMSO) of compound $\mathbf{2 b}$. 


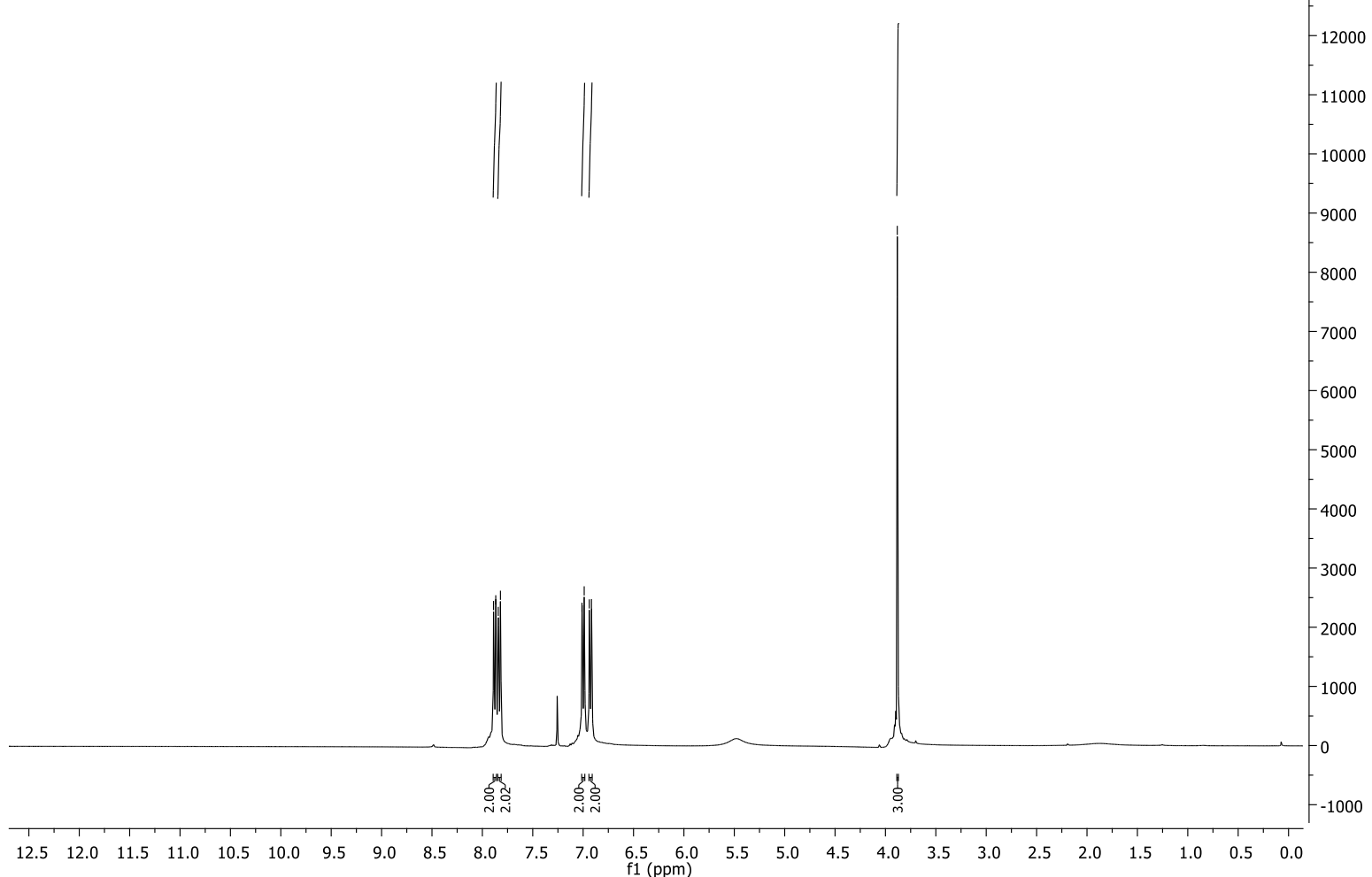

Figure S3: ${ }^{1} \mathrm{H}-\mathrm{NMR}$ spectrum (400 MHz, DMSO) of compound $\mathbf{3 b}$.

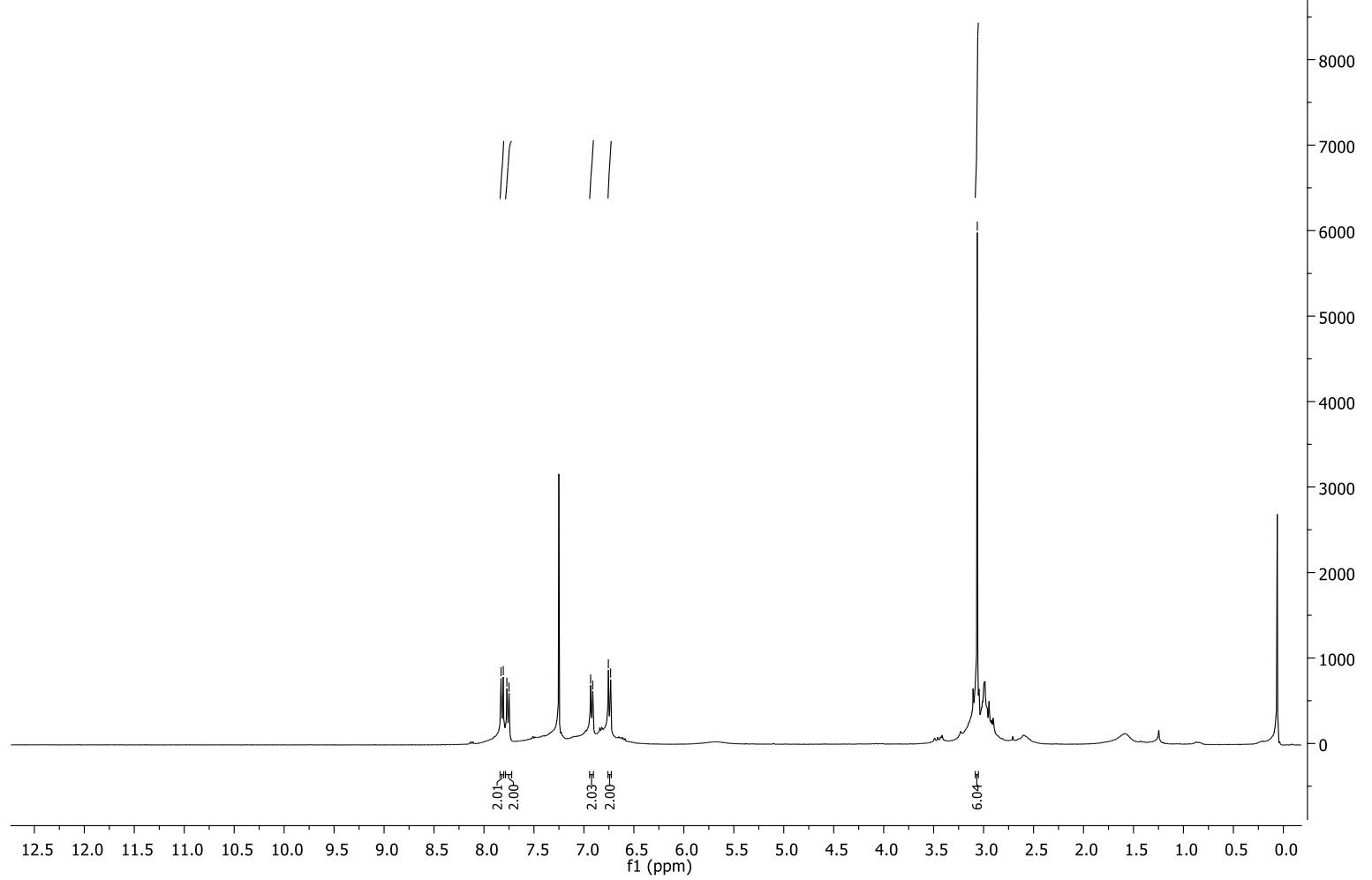

Figure S4: ${ }^{1} \mathrm{H}-\mathrm{NMR}$ spectrum (400 MHz, DMSO) of compound $\mathbf{4 b}$. 


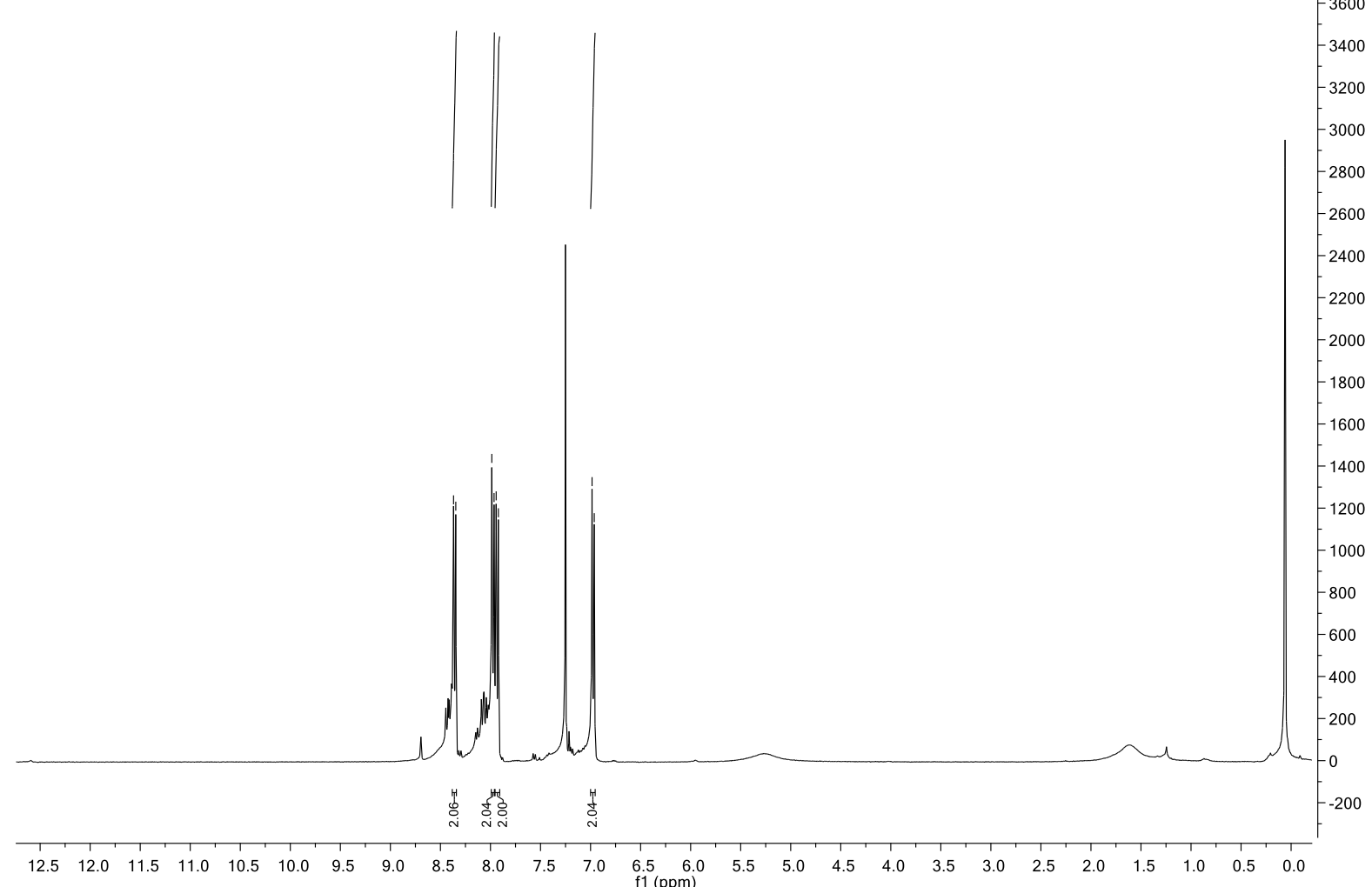

Figure S5: ${ }^{1} \mathrm{H}-\mathrm{NMR}$ spectrum (400 MHz, DMSO) of compound $\mathbf{5 b}$.

NMR 19-01-22

$1 \mathrm{H}$ NMR Paper 1 compound $1 \mathrm{c}$
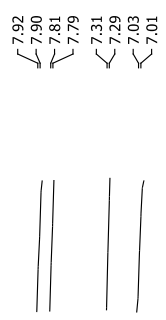

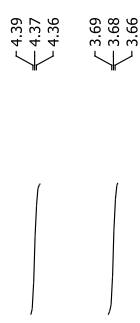

$-9000$

8000

7000

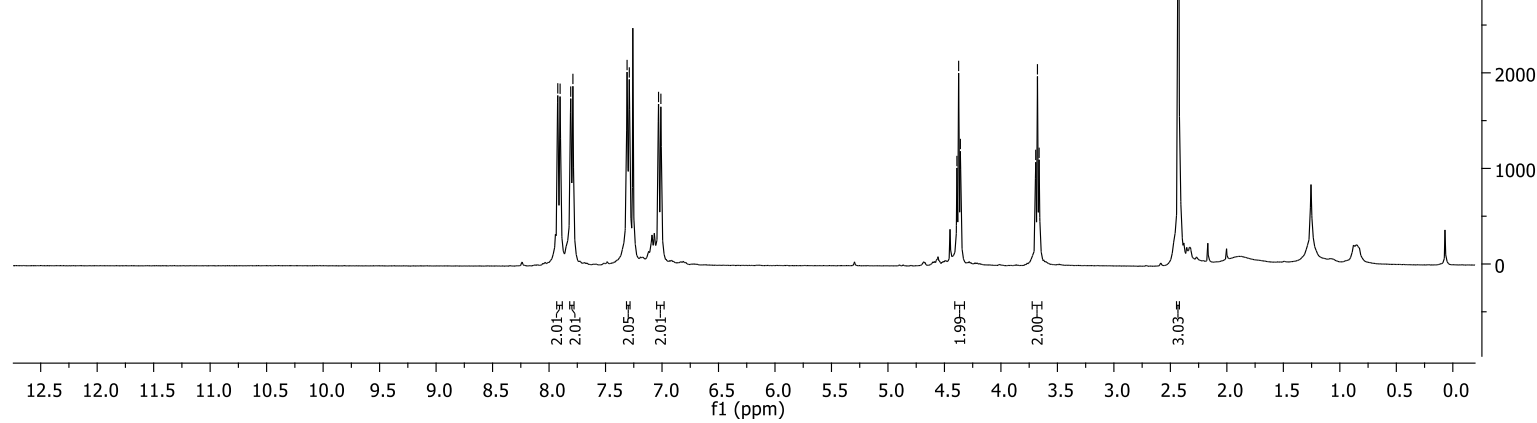

Figure S6: ${ }^{1} \mathrm{H}-\mathrm{NMR}$ spectrum (400 MHz, DMSO) of compound 1c. 


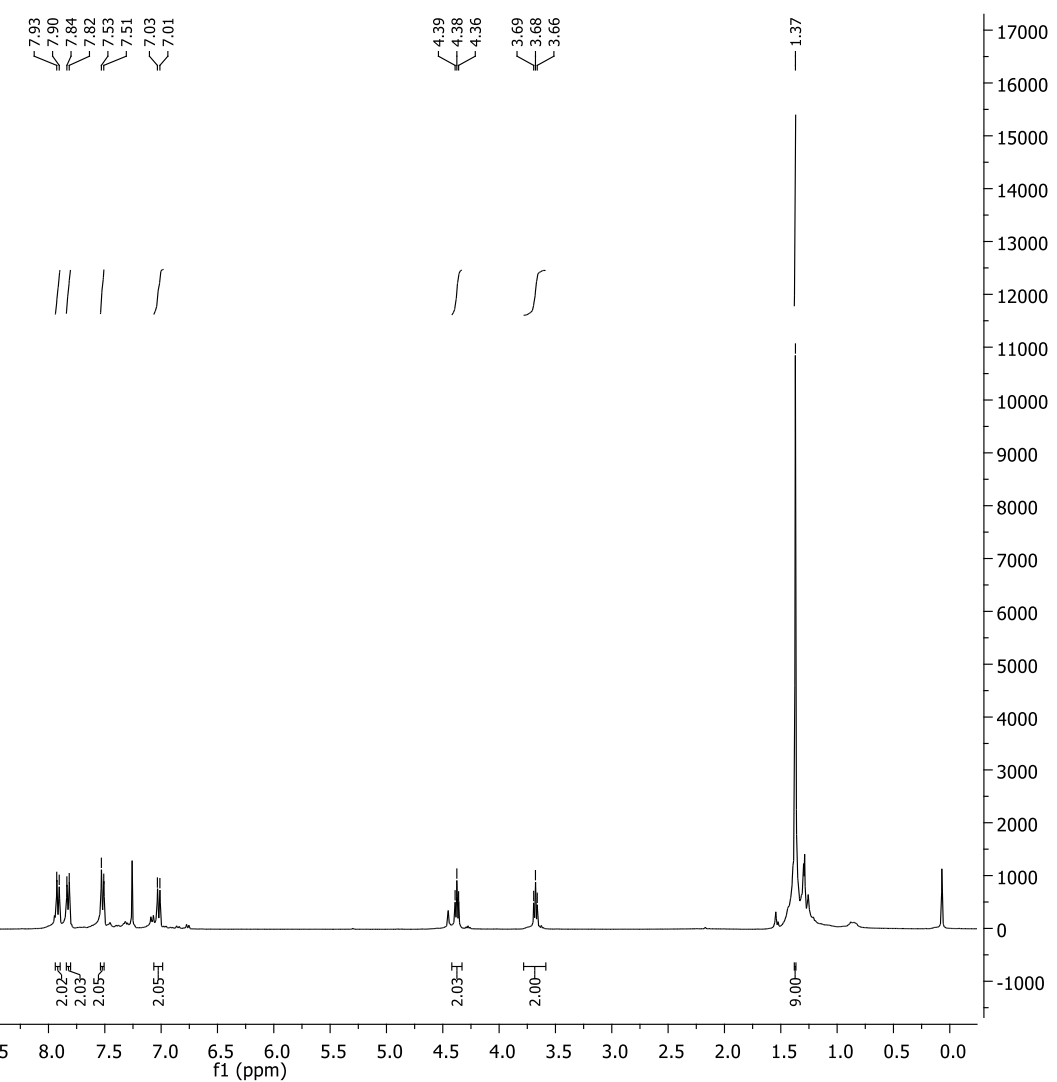

Figure S7: ${ }^{1} \mathrm{H}-\mathrm{NMR}$ spectrum (400 MHz, DMSO) of compound $\mathbf{2 c}$.

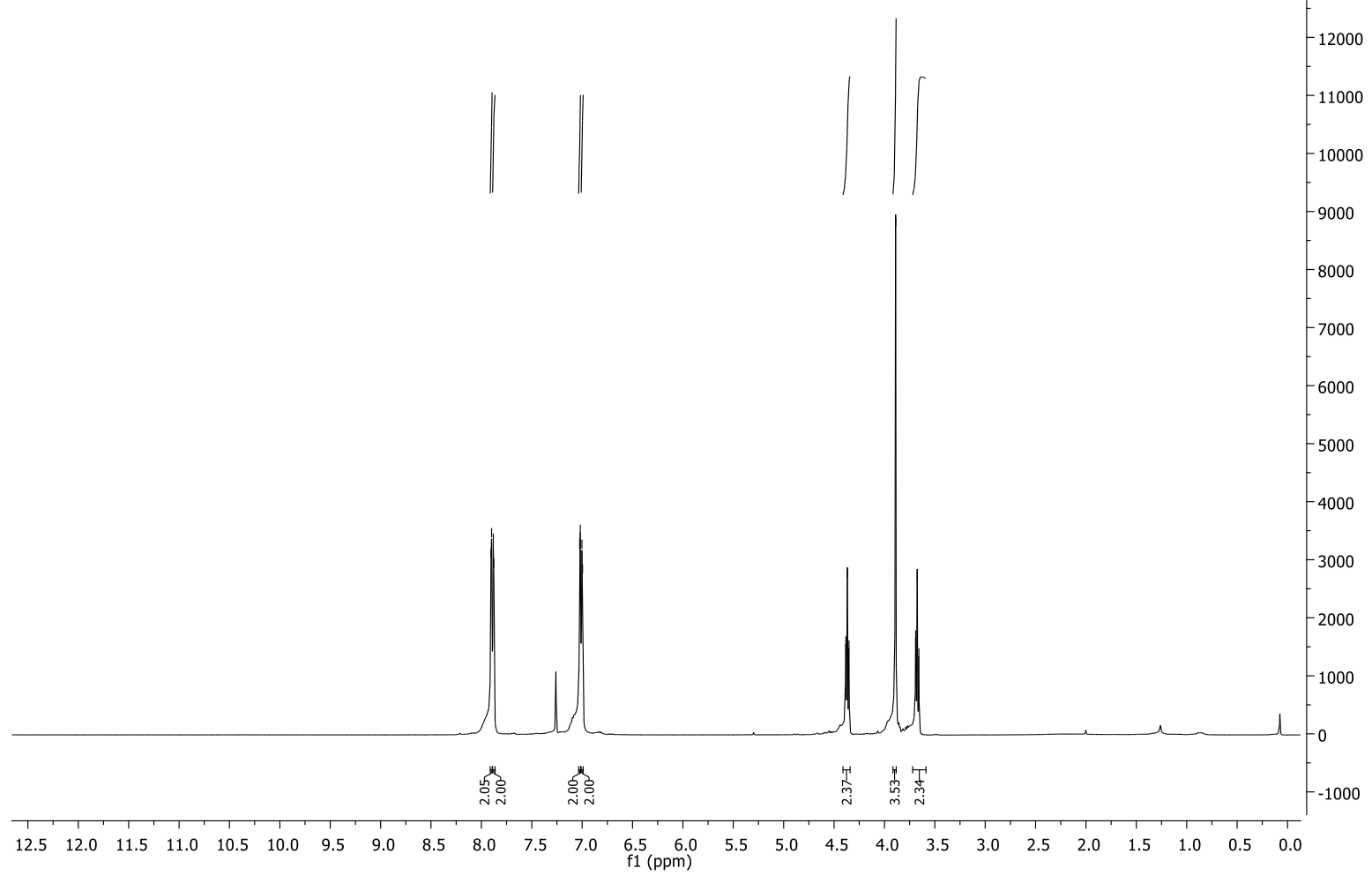

Figure S8: ${ }^{1} \mathrm{H}-\mathrm{NMR}$ spectrum (400 MHz, DMSO) of compound 3c. 


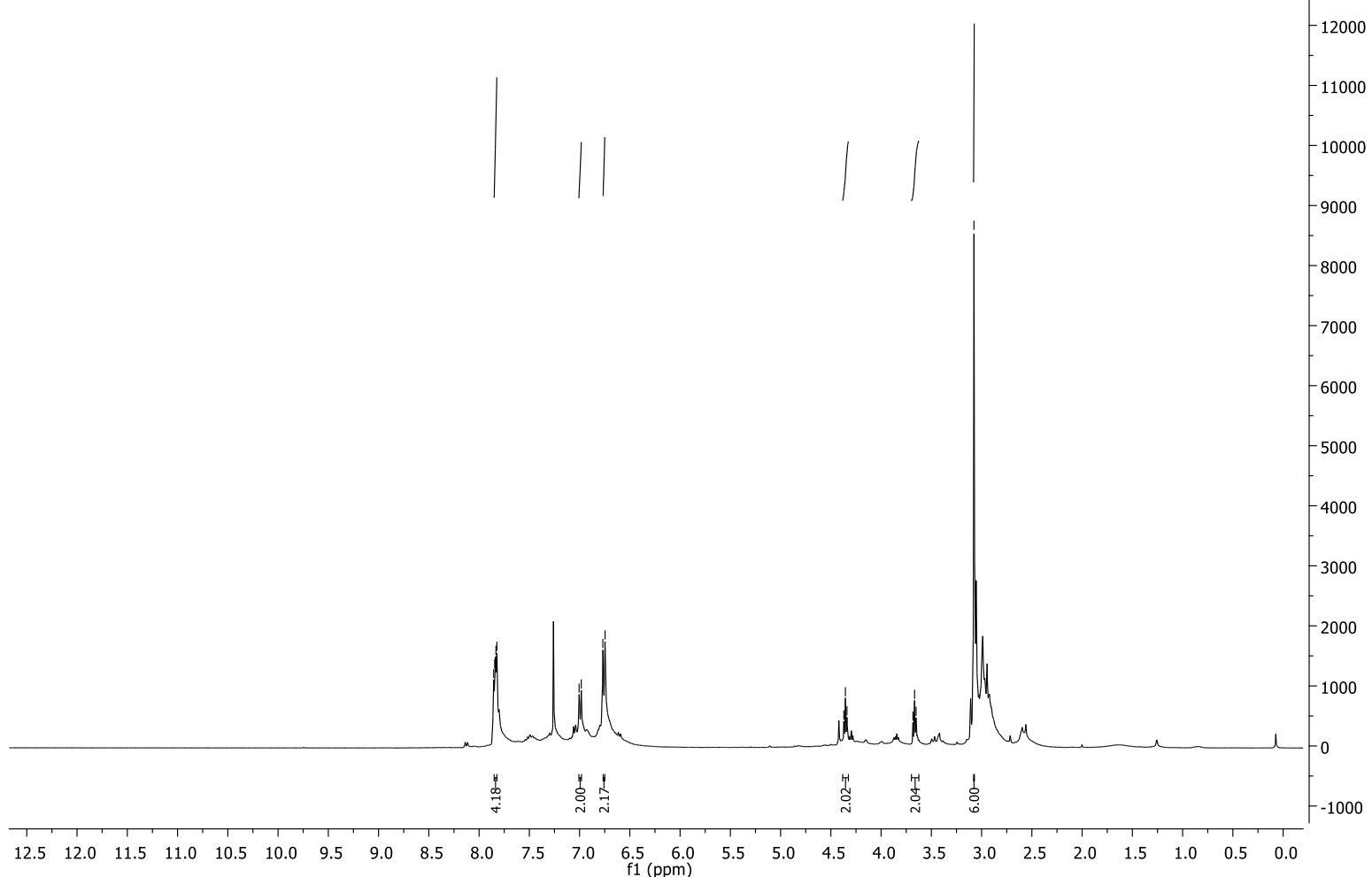

Figure S9: ${ }^{1} \mathrm{H}-\mathrm{NMR}$ spectrum (400 MHz, DMSO) of compound $4 \mathrm{c}$.

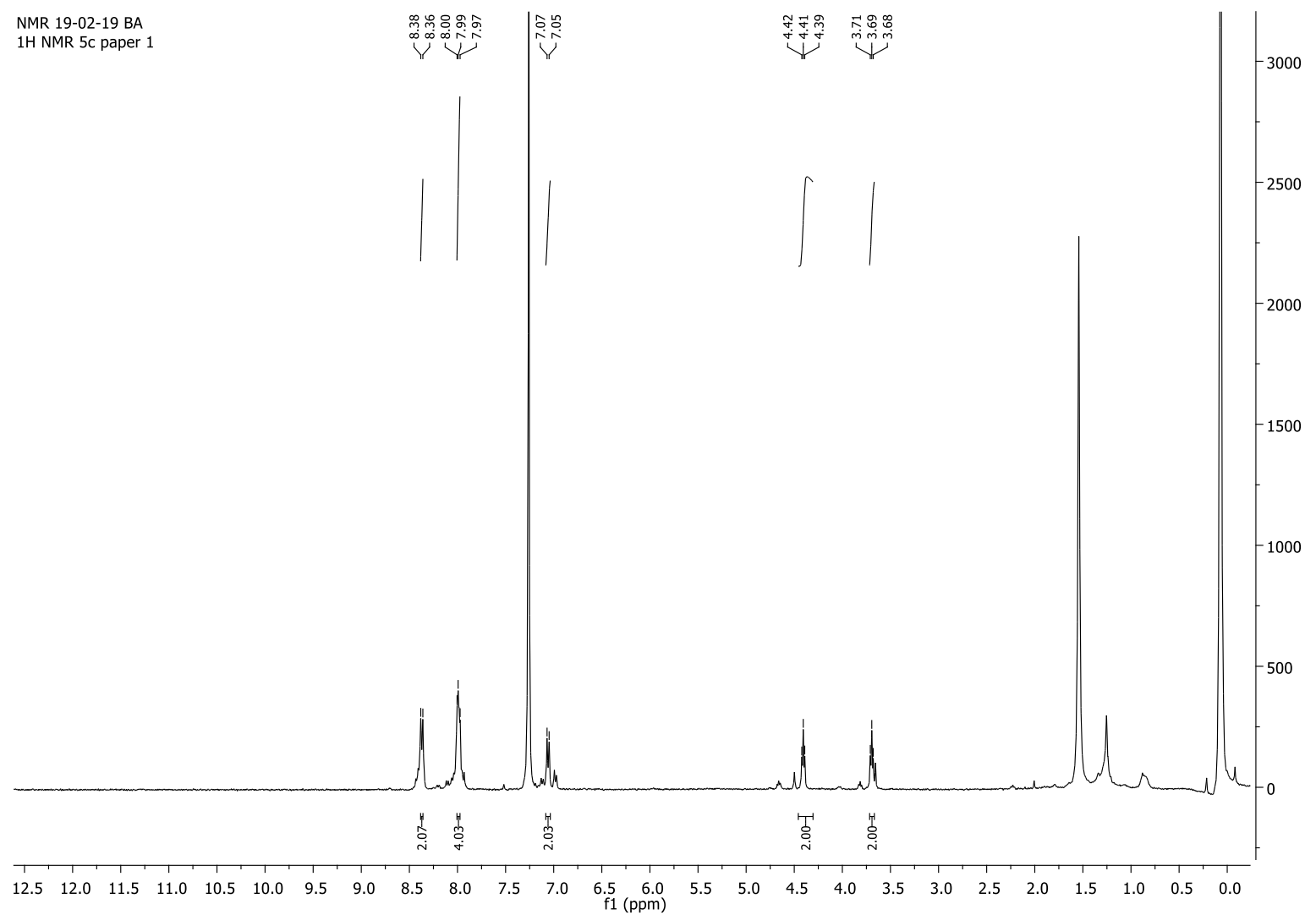

Figure S10: ${ }^{1} \mathrm{H}-\mathrm{NMR}$ spectrum (400 MHz, DMSO) of compound $\mathbf{5 c}$. 


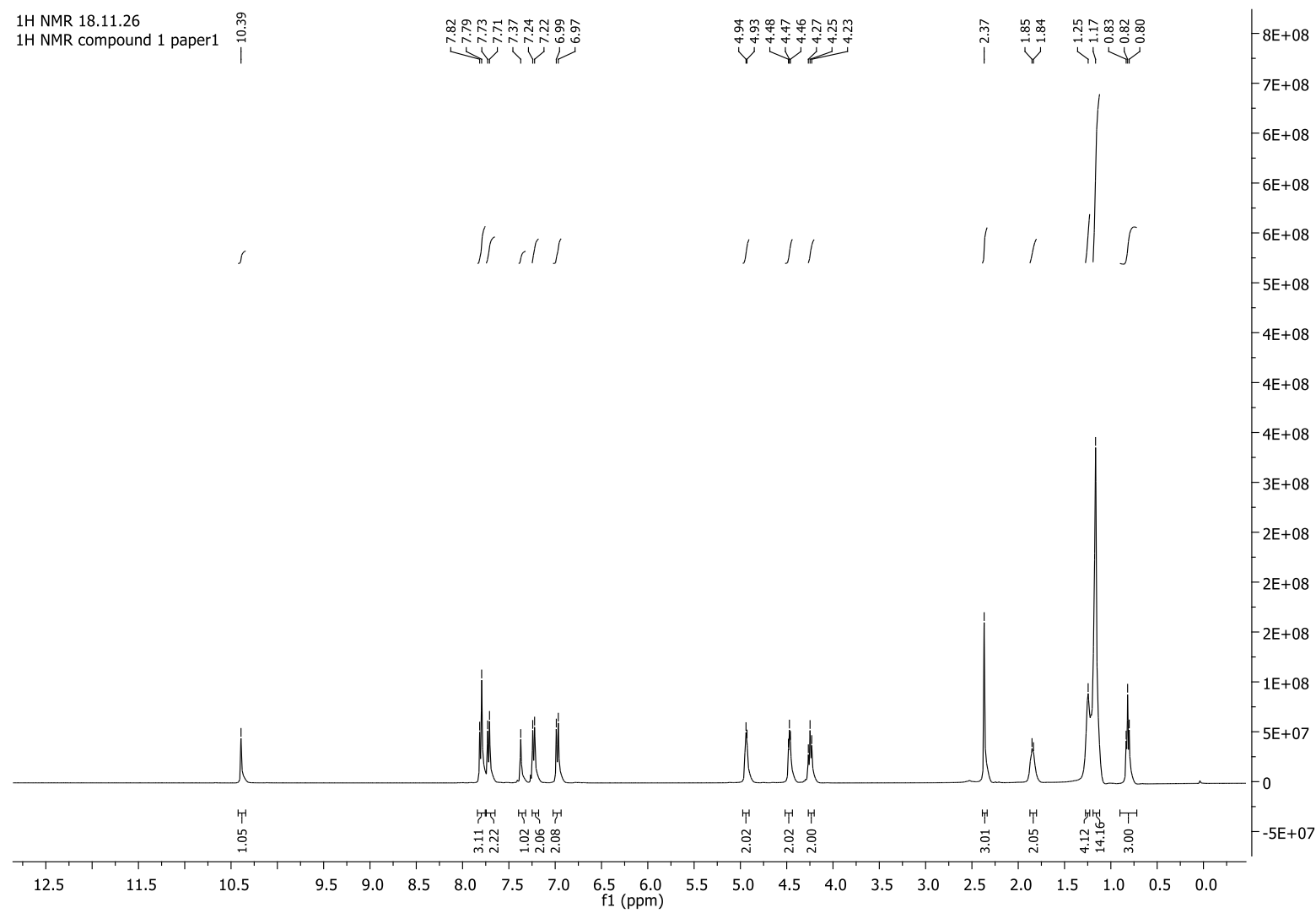

Figure S11: ${ }^{1} \mathrm{H}-\mathrm{NMR}$ spectrum (400 MHz, DMSO) of compound 1.

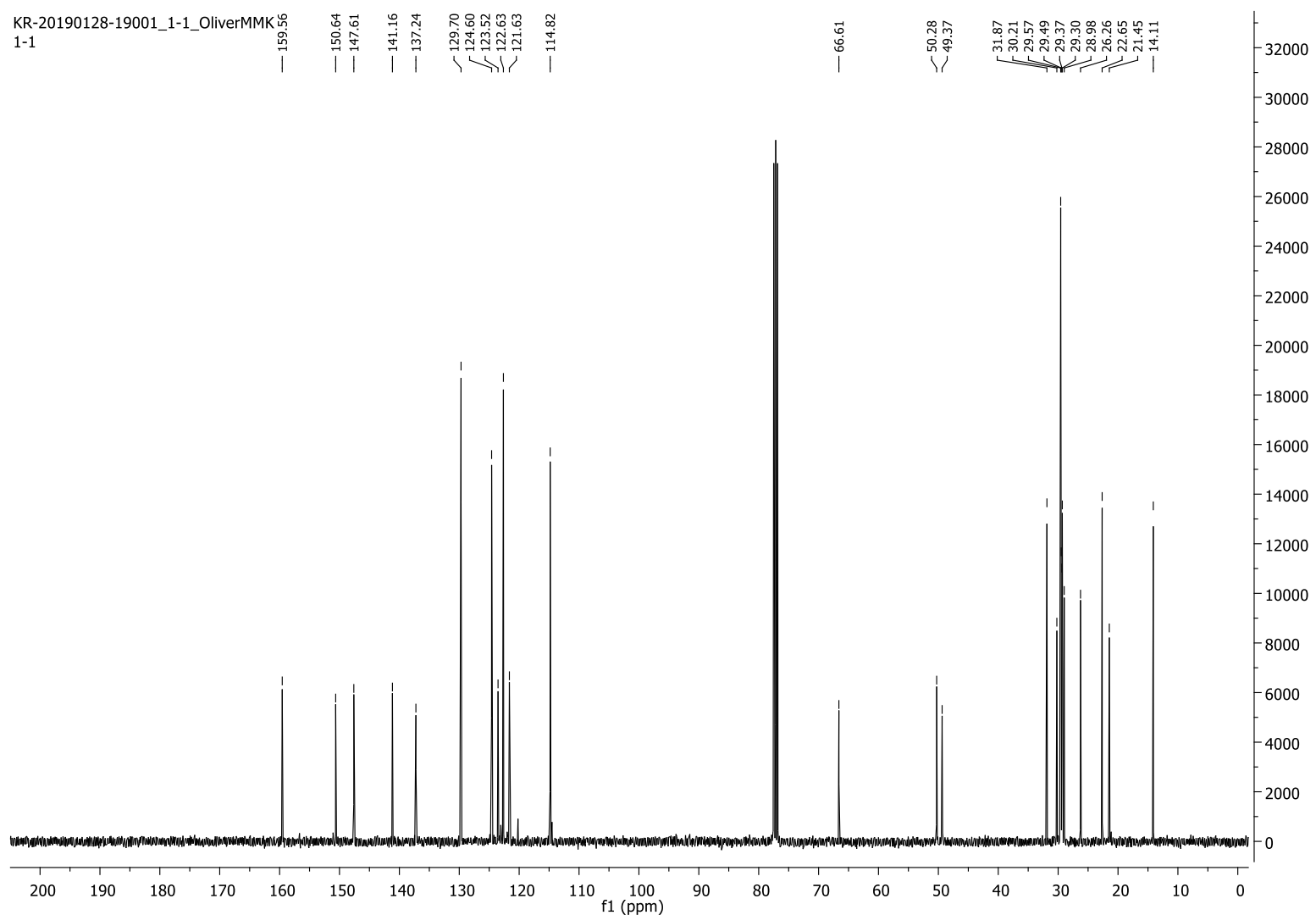

Figure S12: ${ }^{13} \mathrm{C}-\mathrm{NMR}$ spectrum (100 MHz, DMSO) of compound 1. 


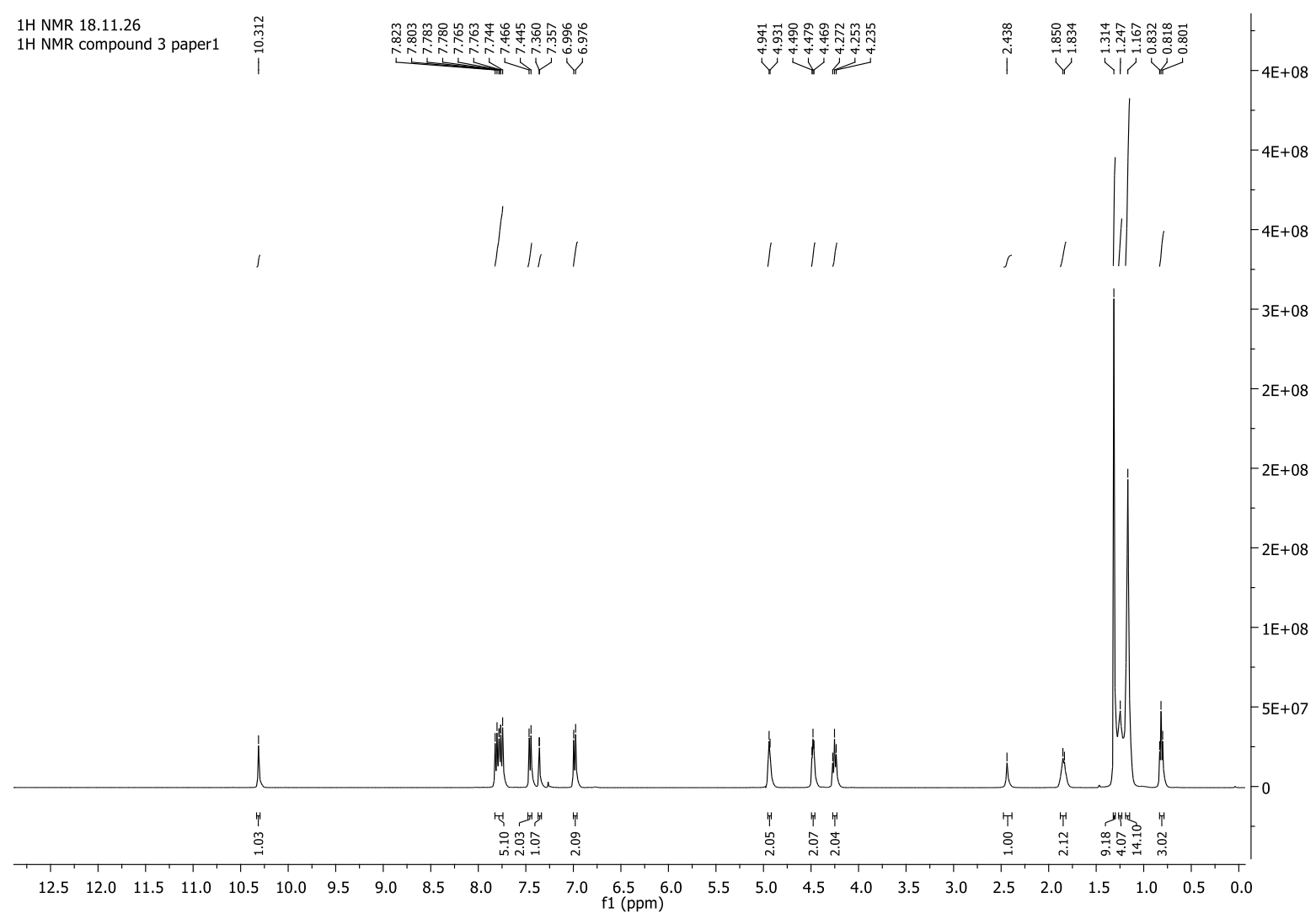

Figure S13: ${ }^{1} \mathrm{H}-\mathrm{NMR}$ spectrum (400 MHz, DMSO) of compound 2.

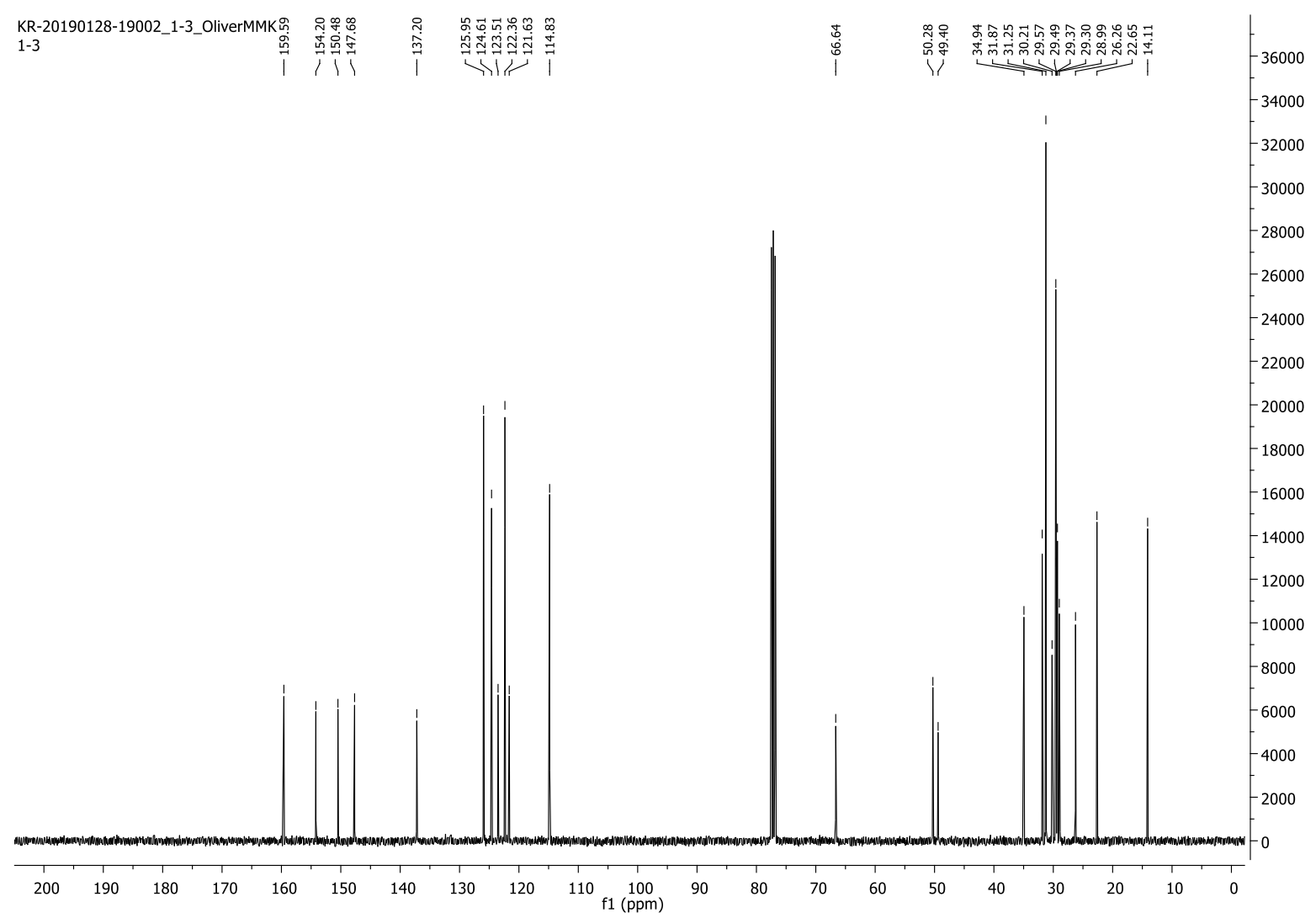

Figure S14: ${ }^{13} \mathrm{C}-\mathrm{NMR}$ spectrum (100 MHz, DMSO) of compound 2. 


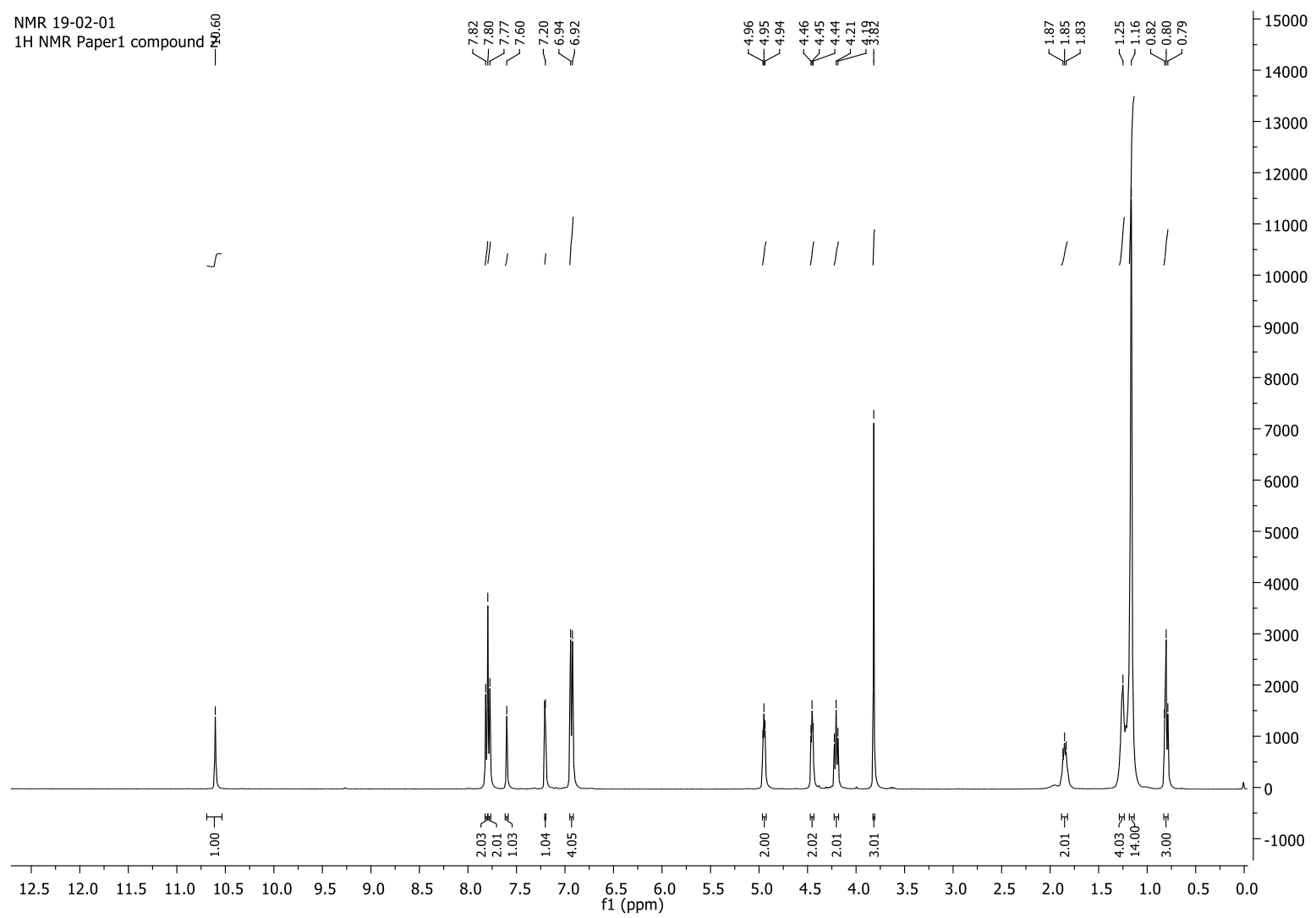

Figure S15: ${ }^{1} \mathrm{H}-\mathrm{NMR}$ spectrum (400 MHz, DMSO) of compound 3.

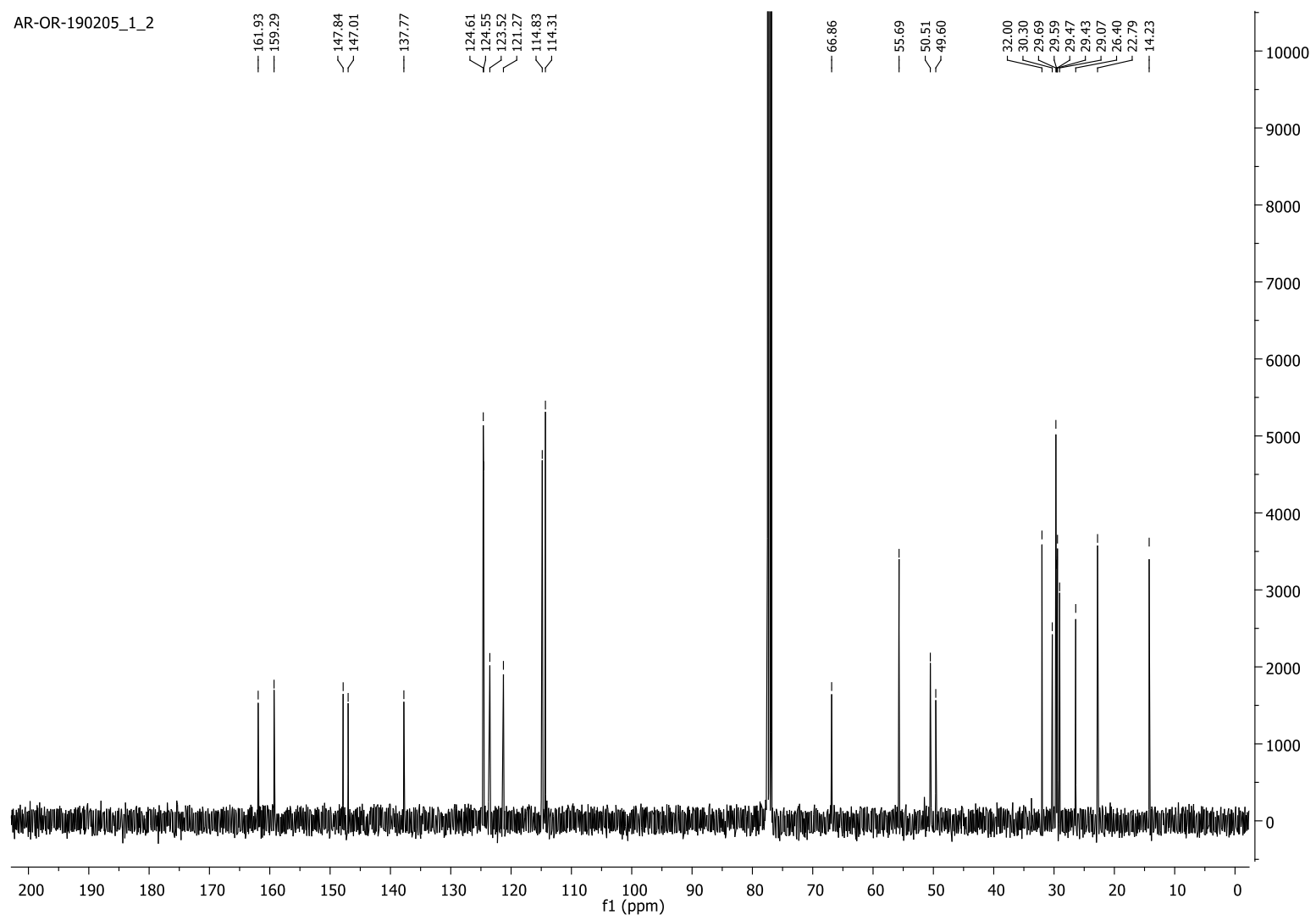

Figure S16: ${ }^{13} \mathrm{C}-\mathrm{NMR}$ spectrum (100 MHz, DMSO) of compound 3. 


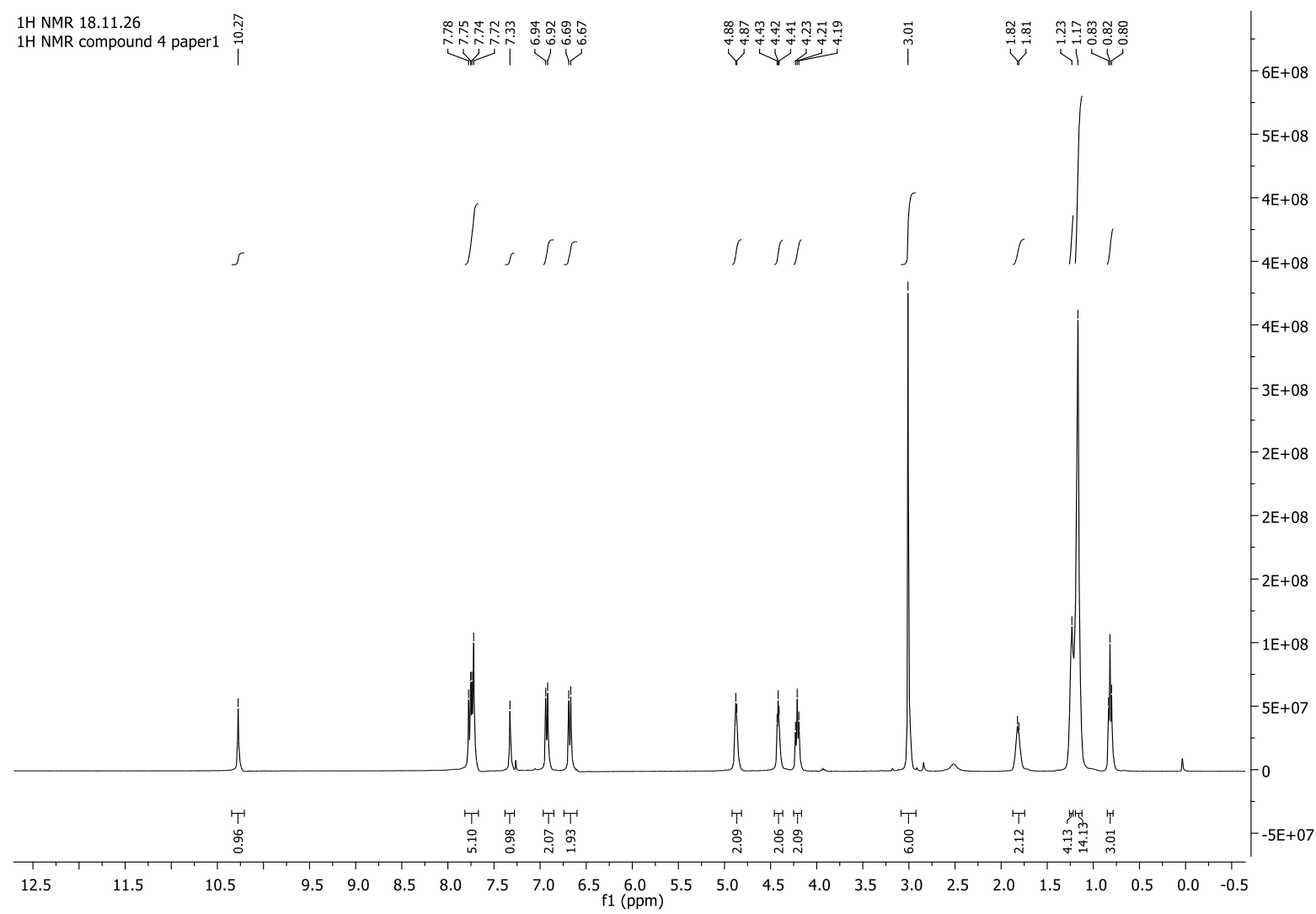

Figure S17: ${ }^{1} \mathrm{H}-\mathrm{NMR}$ spectrum (400 MHz, DMSO) of compound 4.

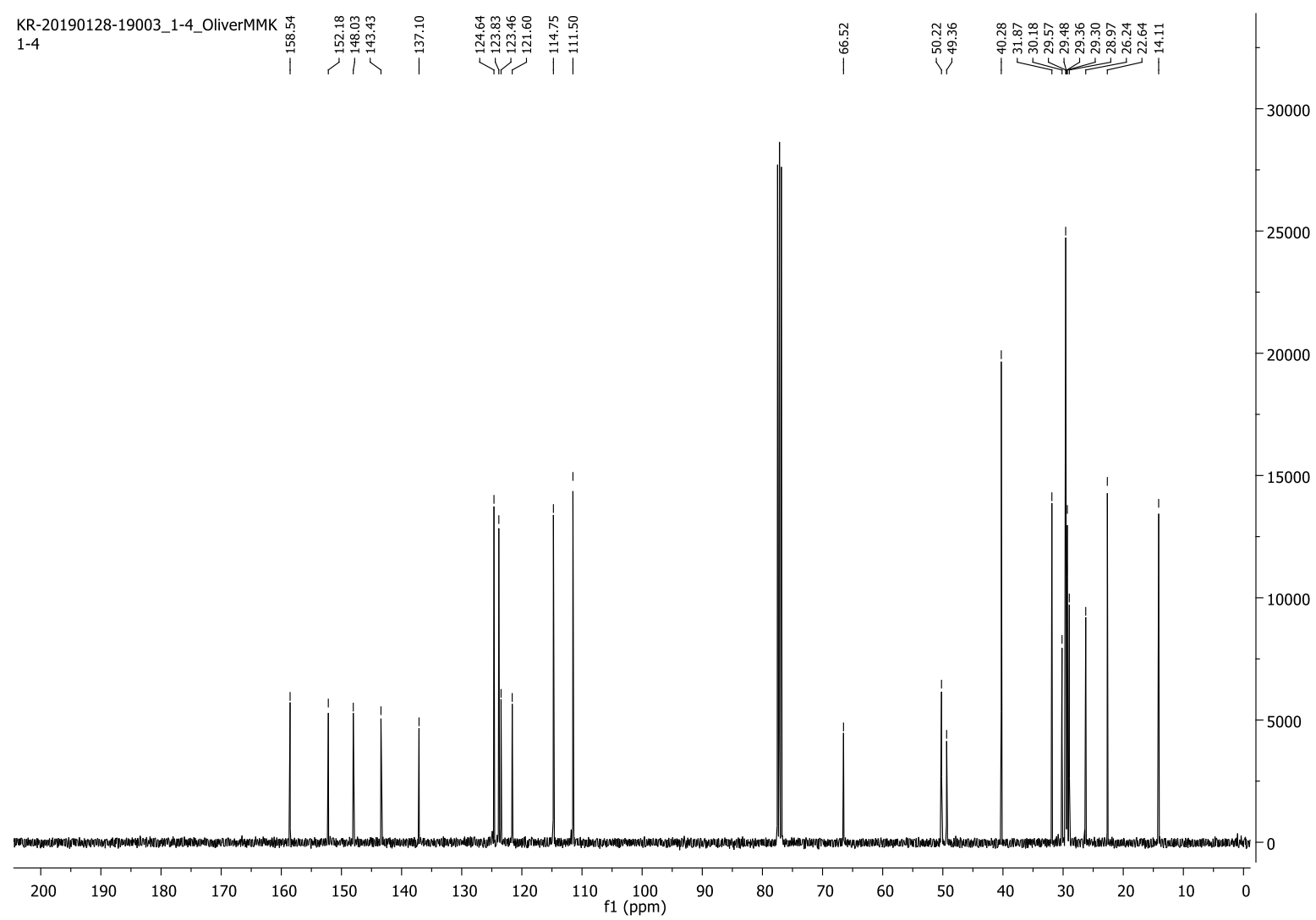

Figure S18: ${ }^{13} \mathrm{C}-\mathrm{NMR}$ spectrum (100 MHz, DMSO) of compound 4. 


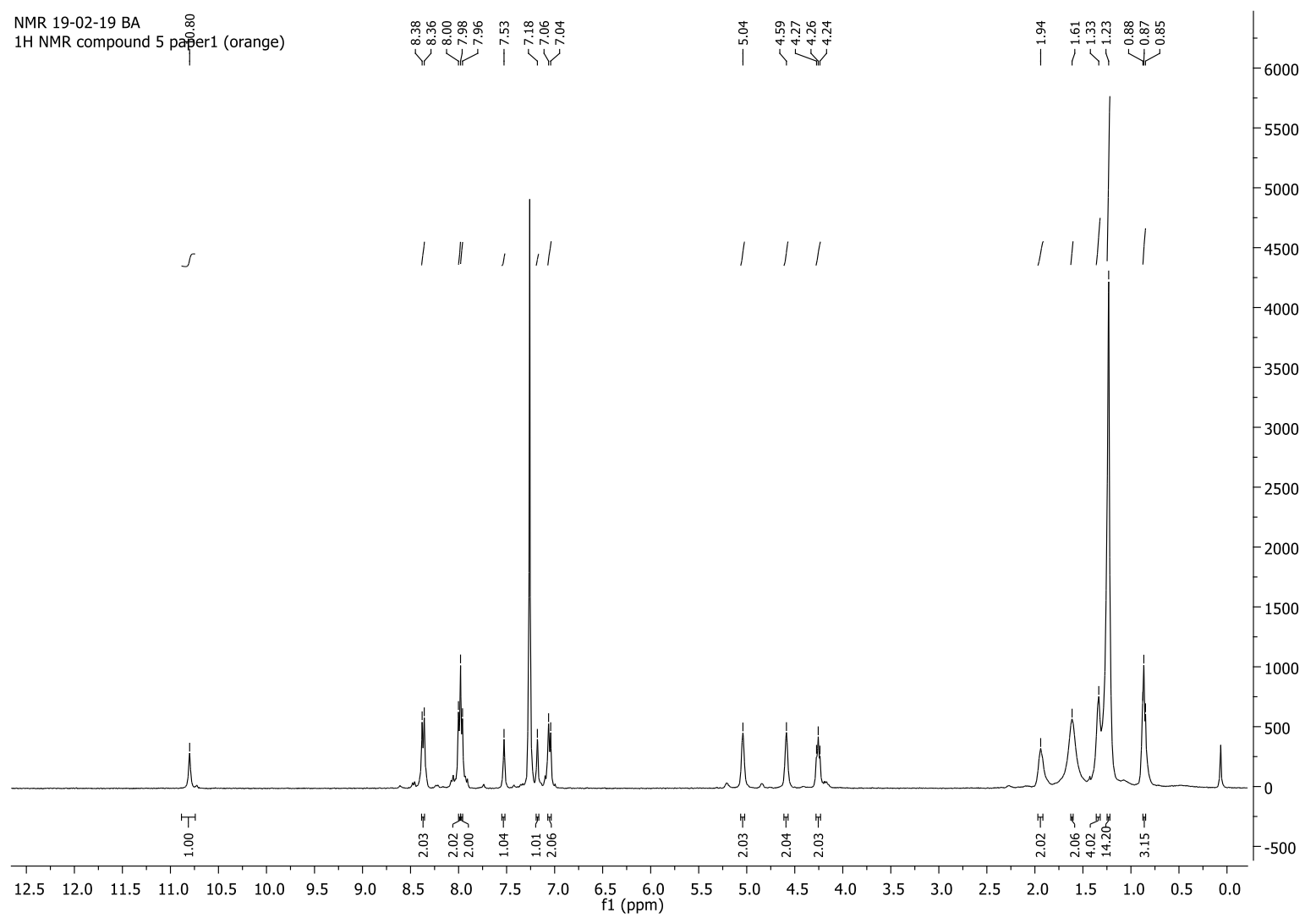

Figure S19: ${ }^{1} \mathrm{H}-\mathrm{NMR}$ spectrum (400 MHz, DMSO) of compound 5.

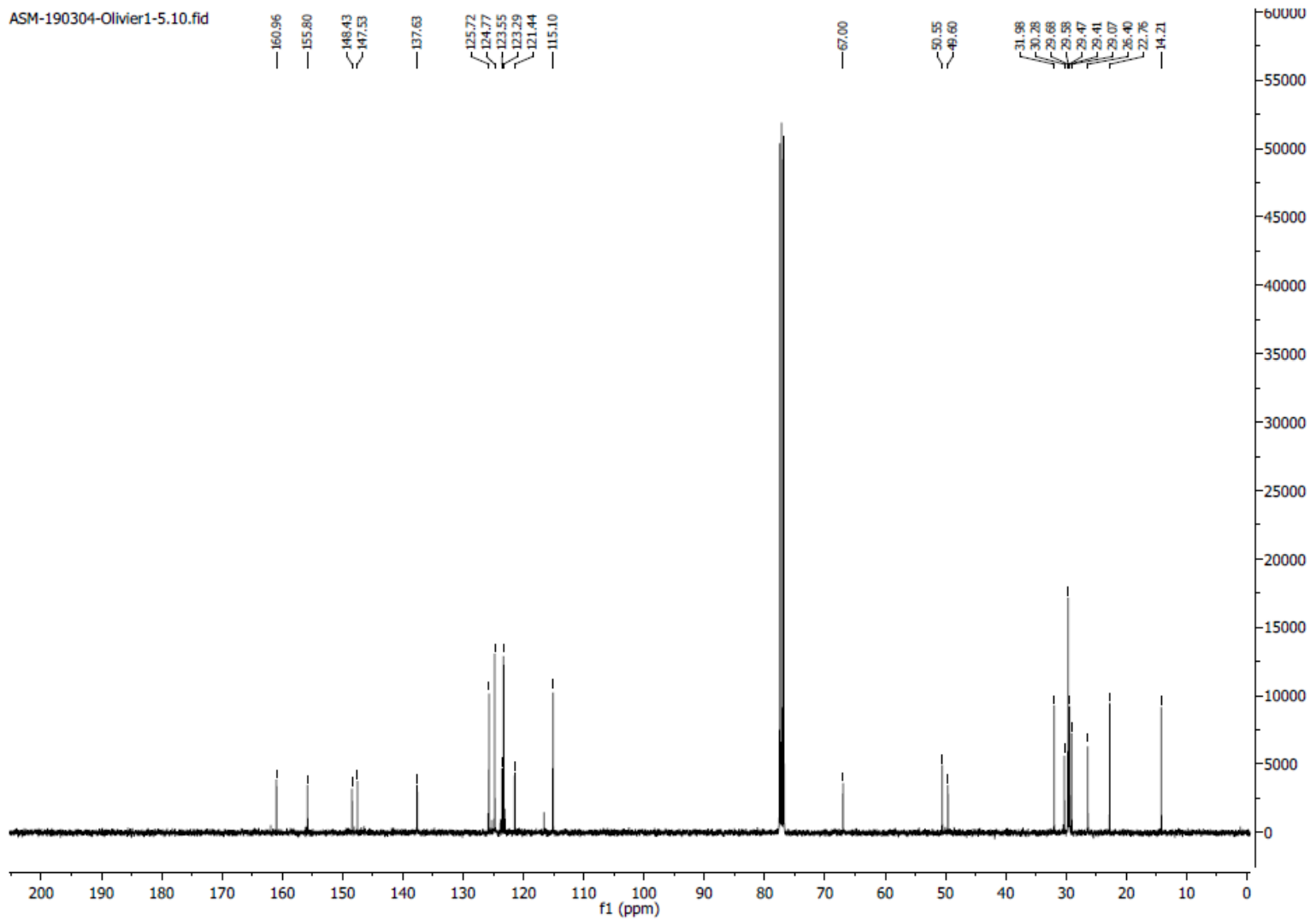

Figure S20: ${ }^{13} \mathrm{C}-\mathrm{NMR}$ spectrum (100 MHz, DMSO) of compound 5. 


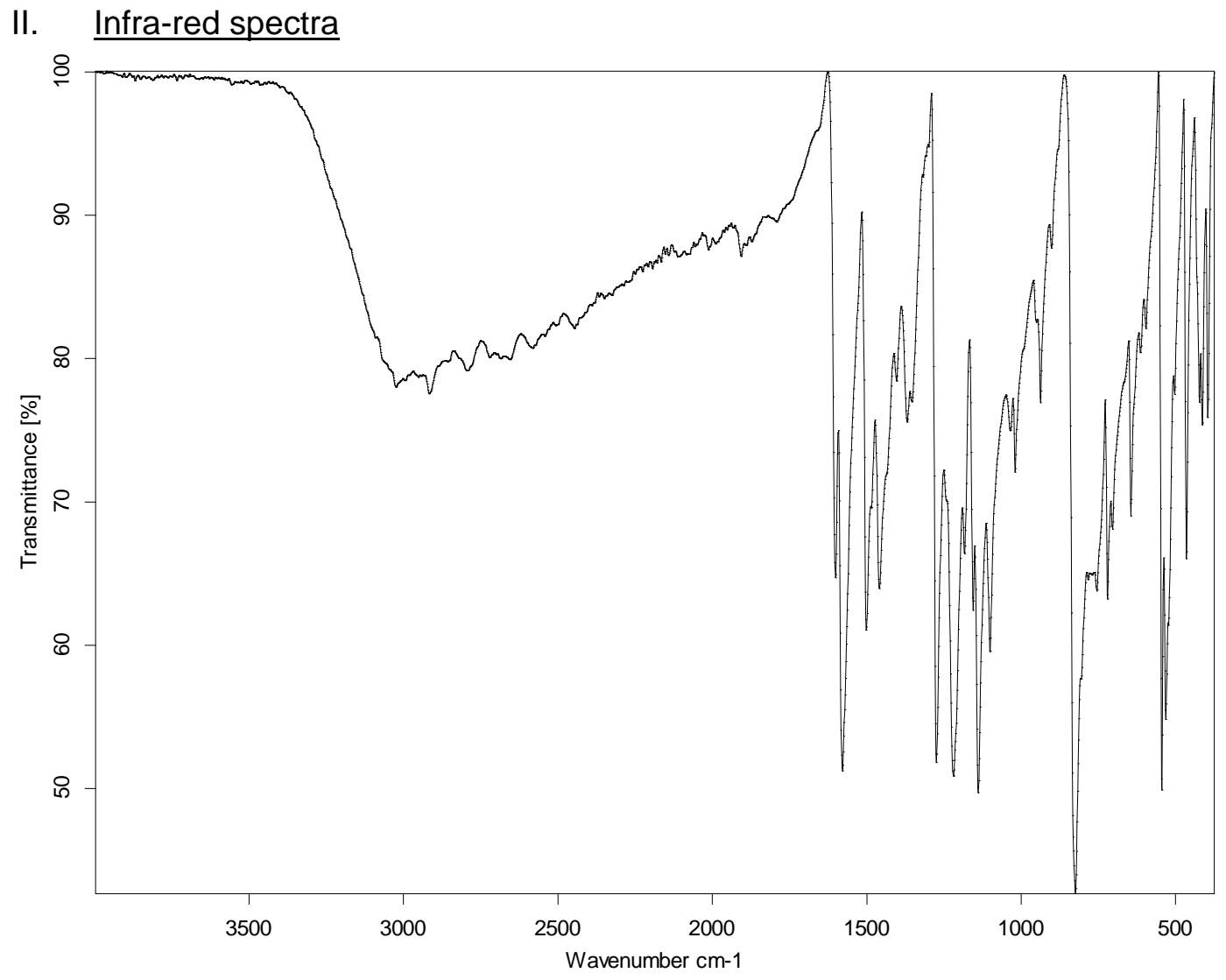

Figure S21: Infra-red spectrum of compound 1b.

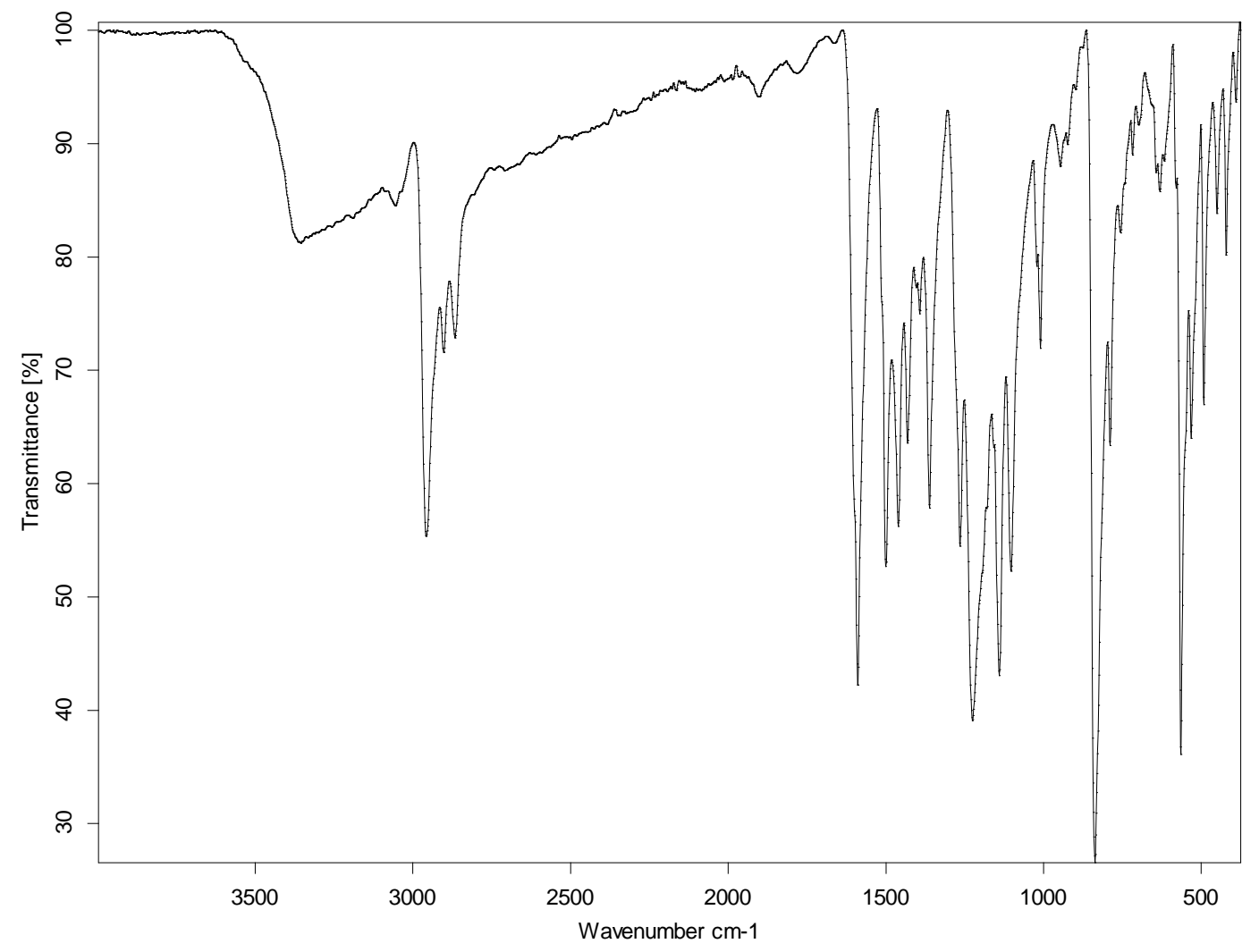

Figure S22: Infra-red spectrum of compound $\mathbf{2 b}$. 


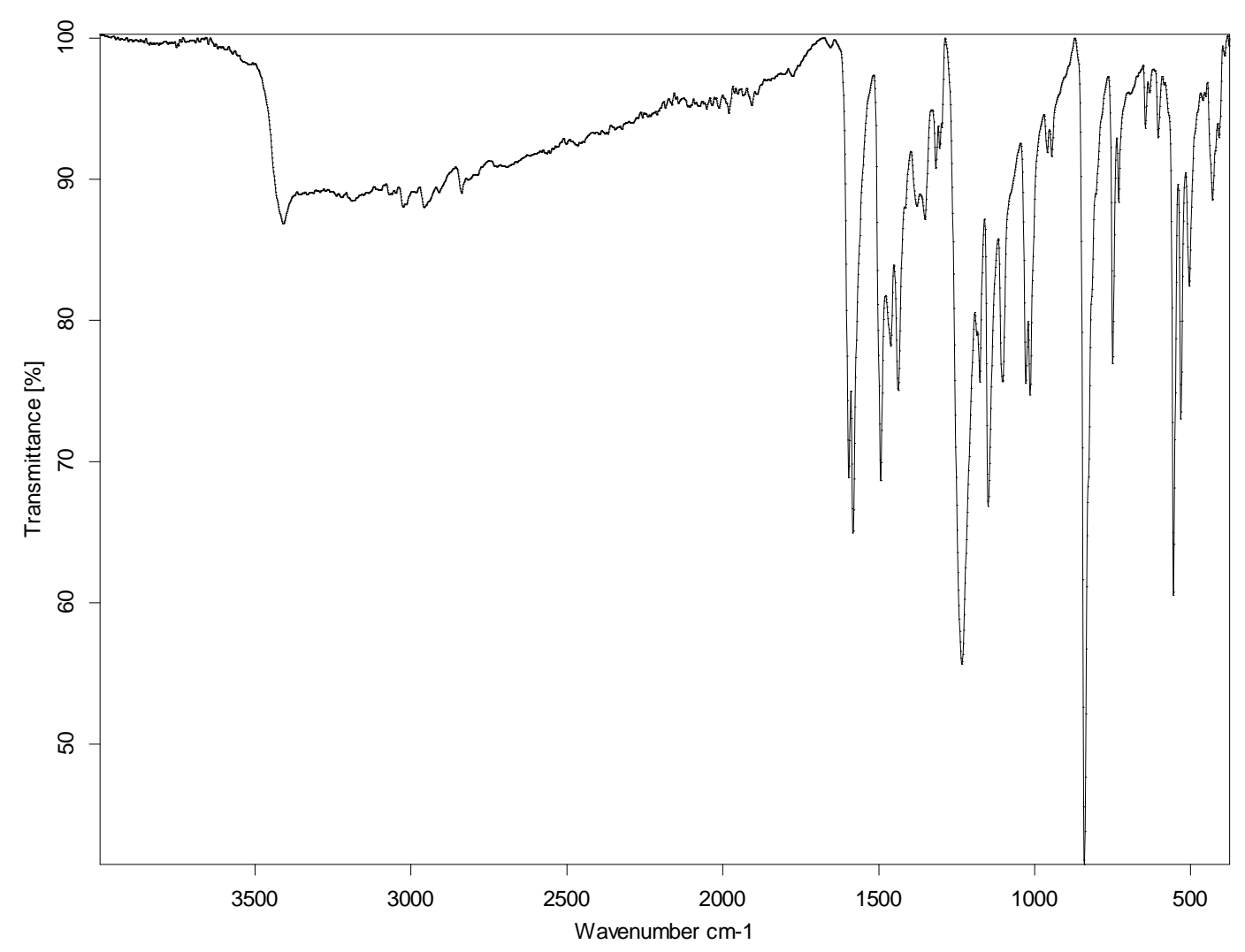

Figure S23: Infra-red spectrum of compound 3b.

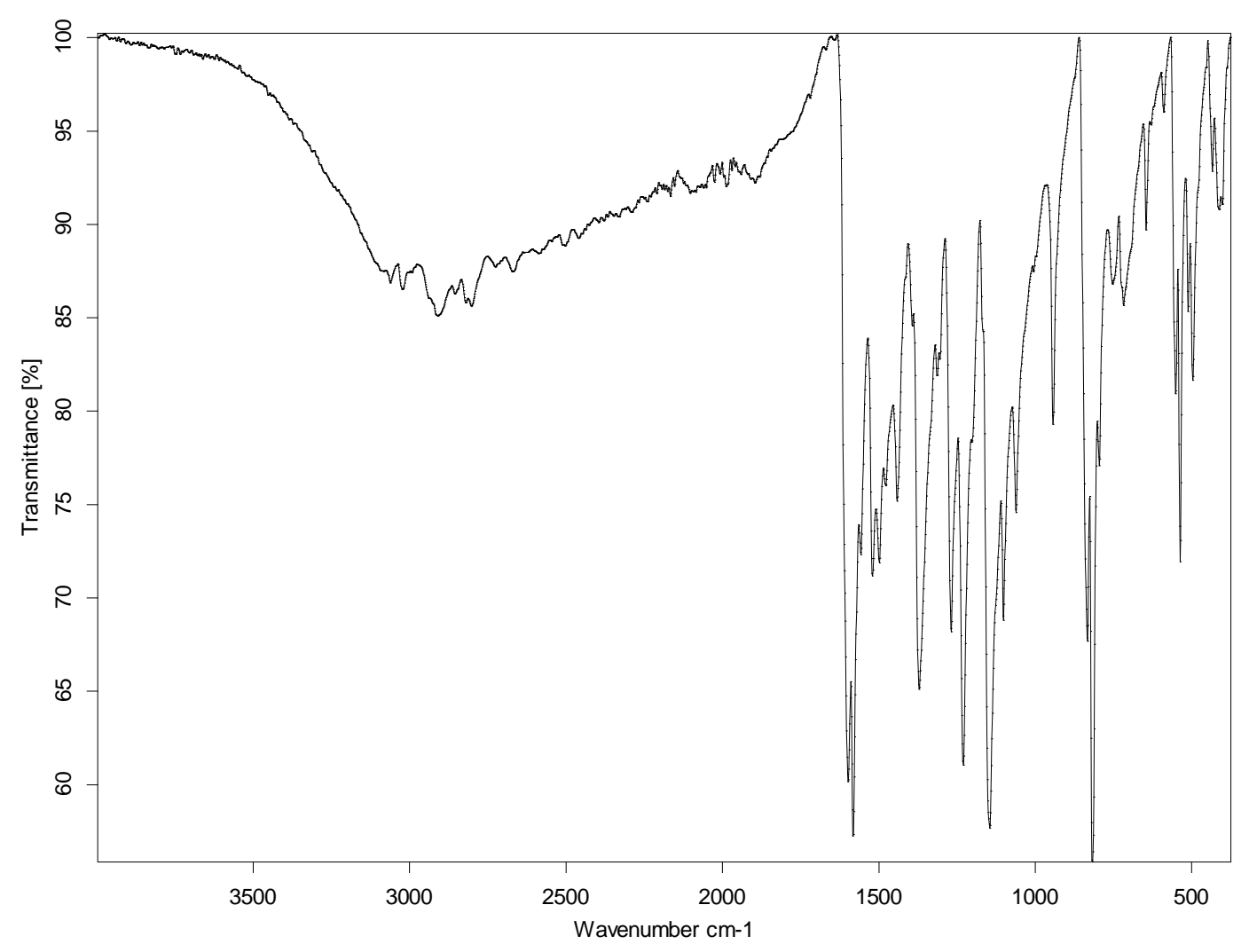

Figure S24: Infra-red spectrum of compound $\mathbf{4 b .}$ 


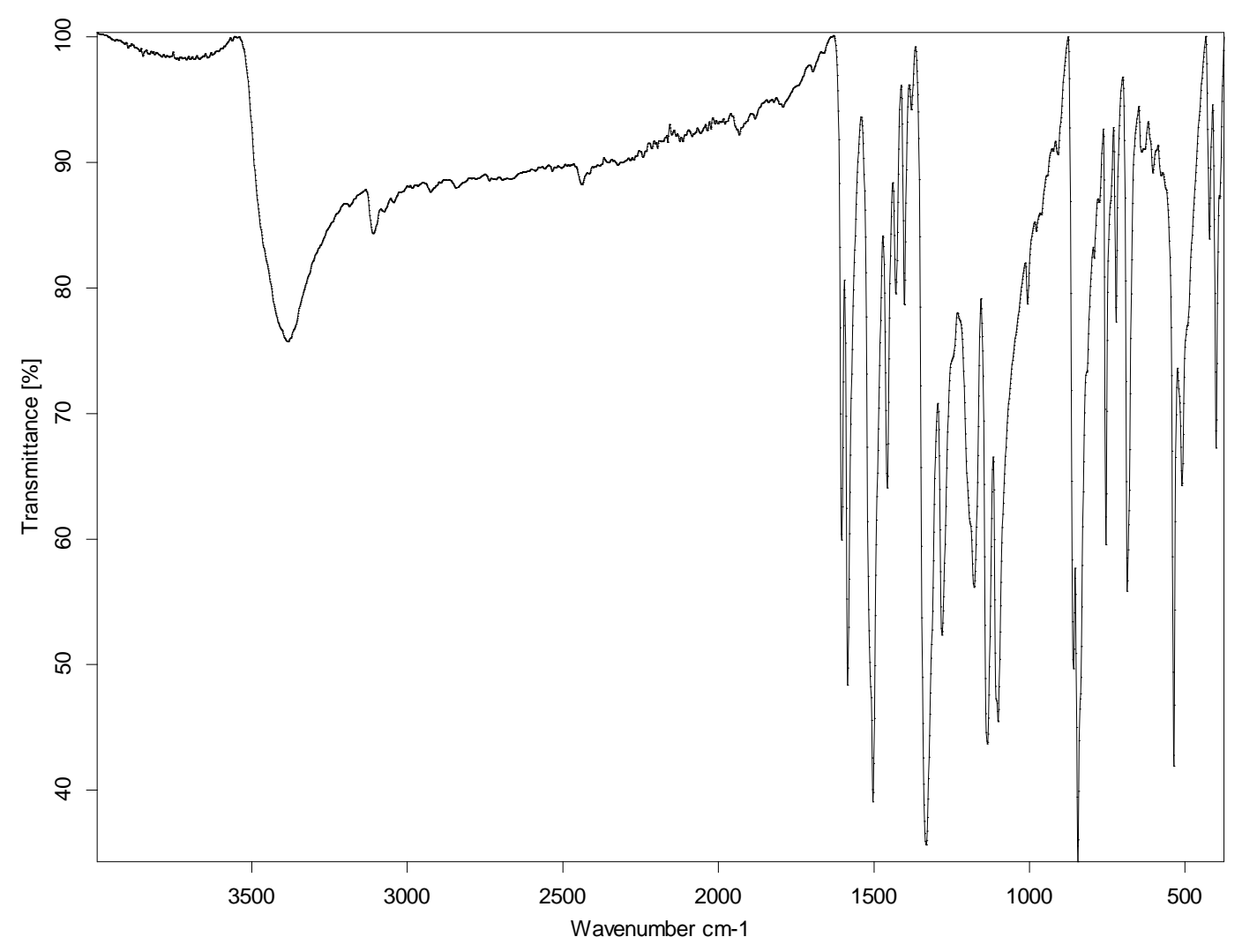

Figure S25: Infra-red spectrum of compound 5b.

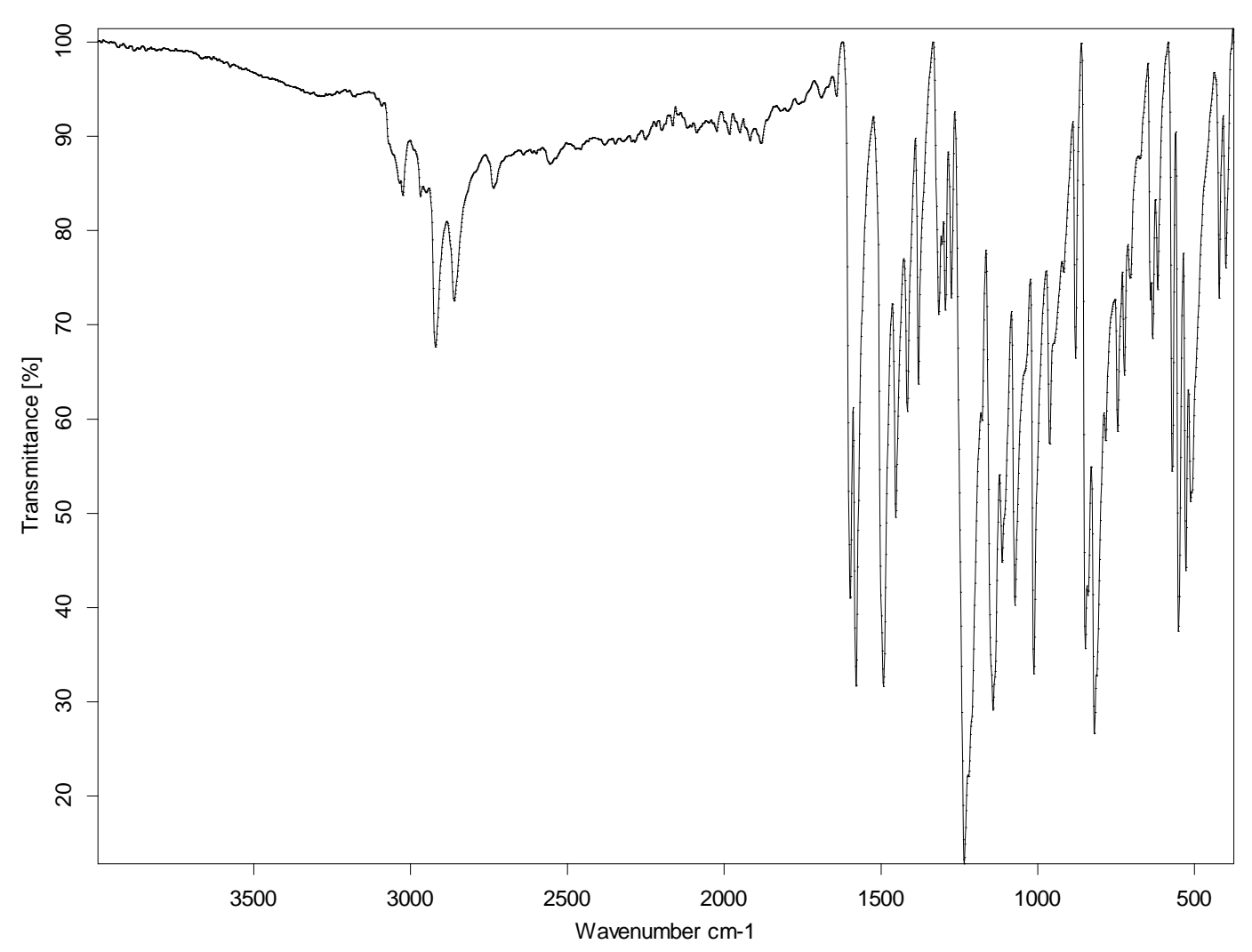

Figure S26: Infra-red spectrum of compound 1c. 


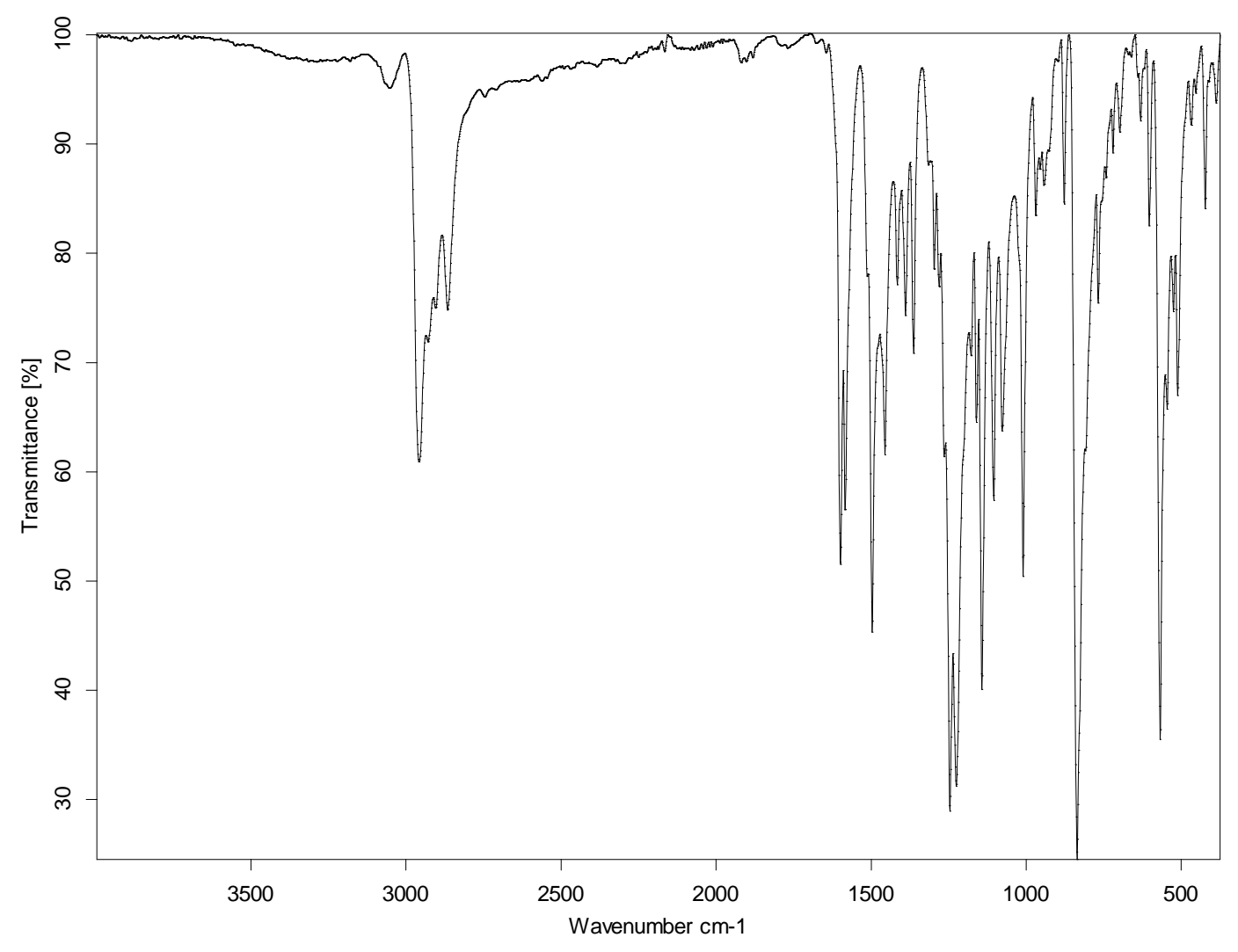

Figure S27: Infra-red spectrum of compound 2c.

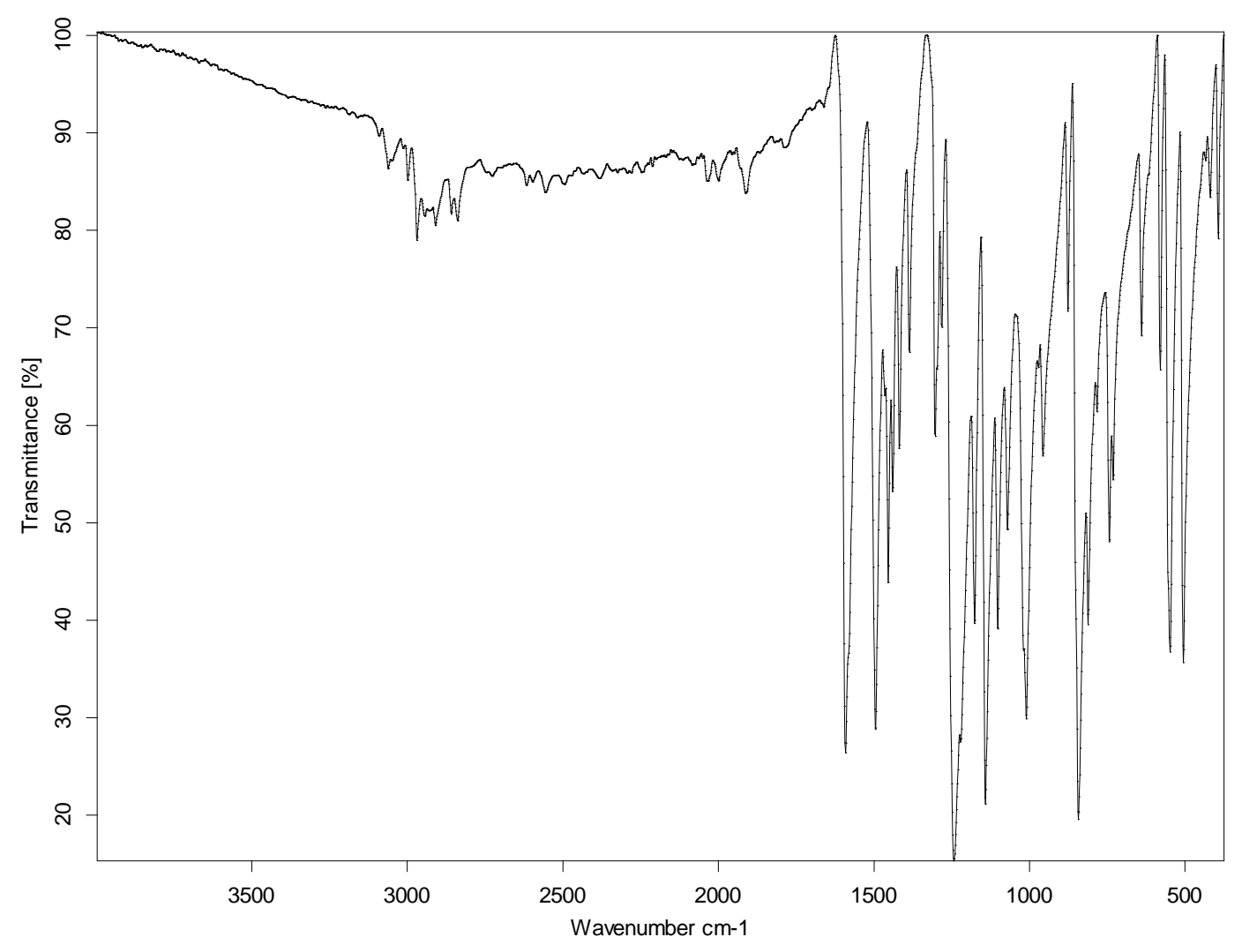

Figure S28: Infra-red spectrum of compound 3c. 


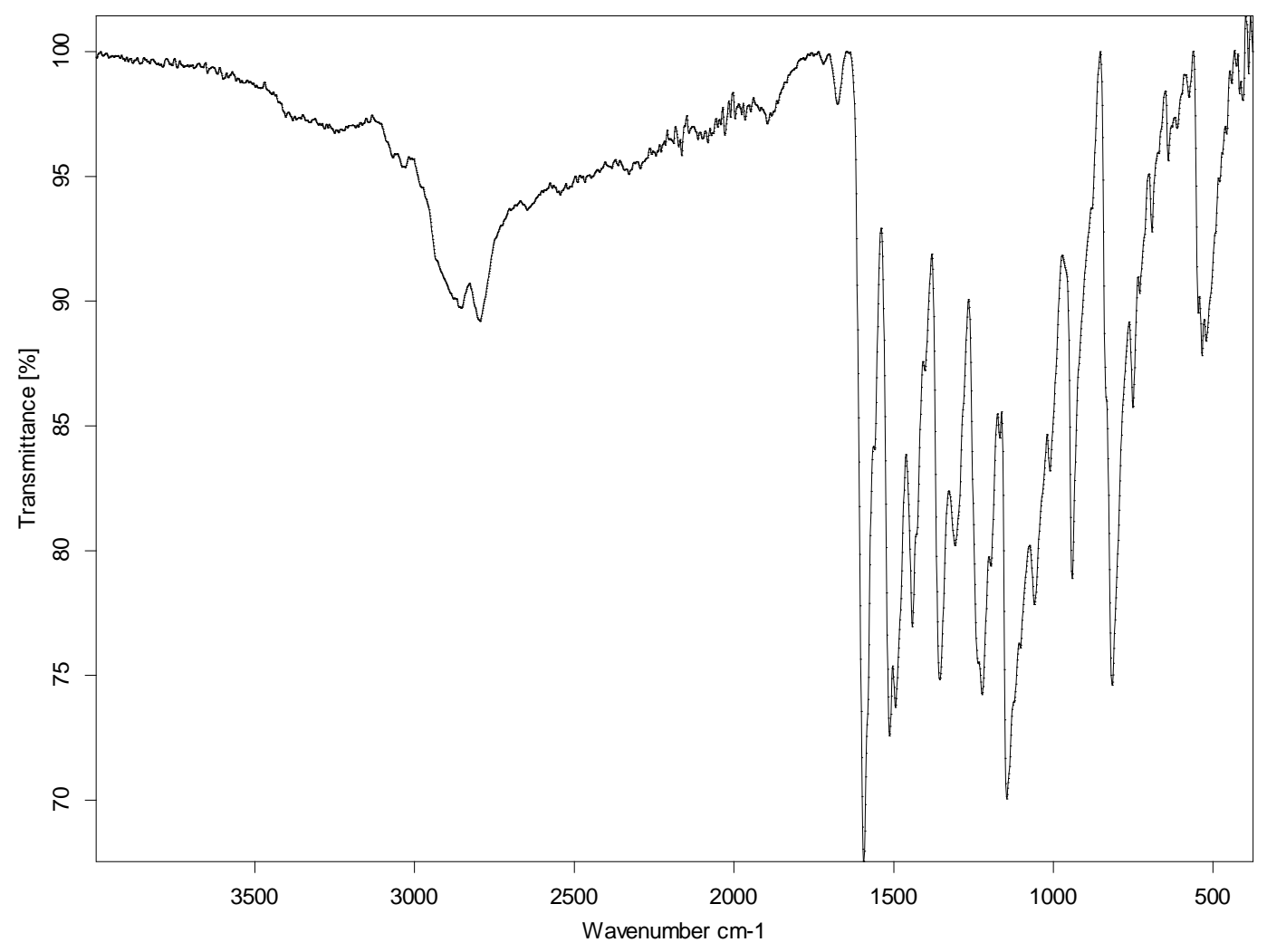

Figure S29: Infra-red spectrum of compound 4c.

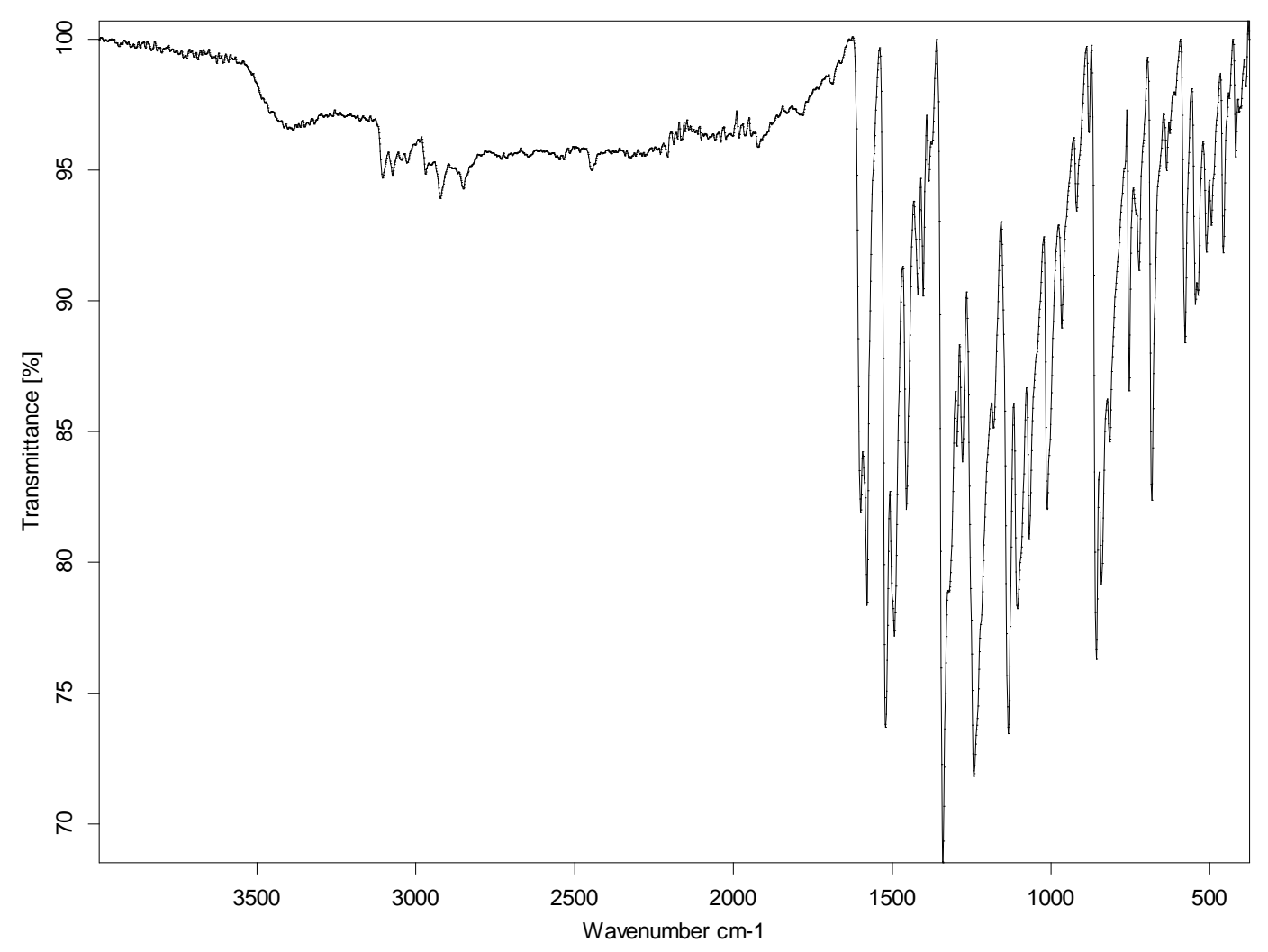

Figure S30: Infra-red spectrum of compound 5c. 


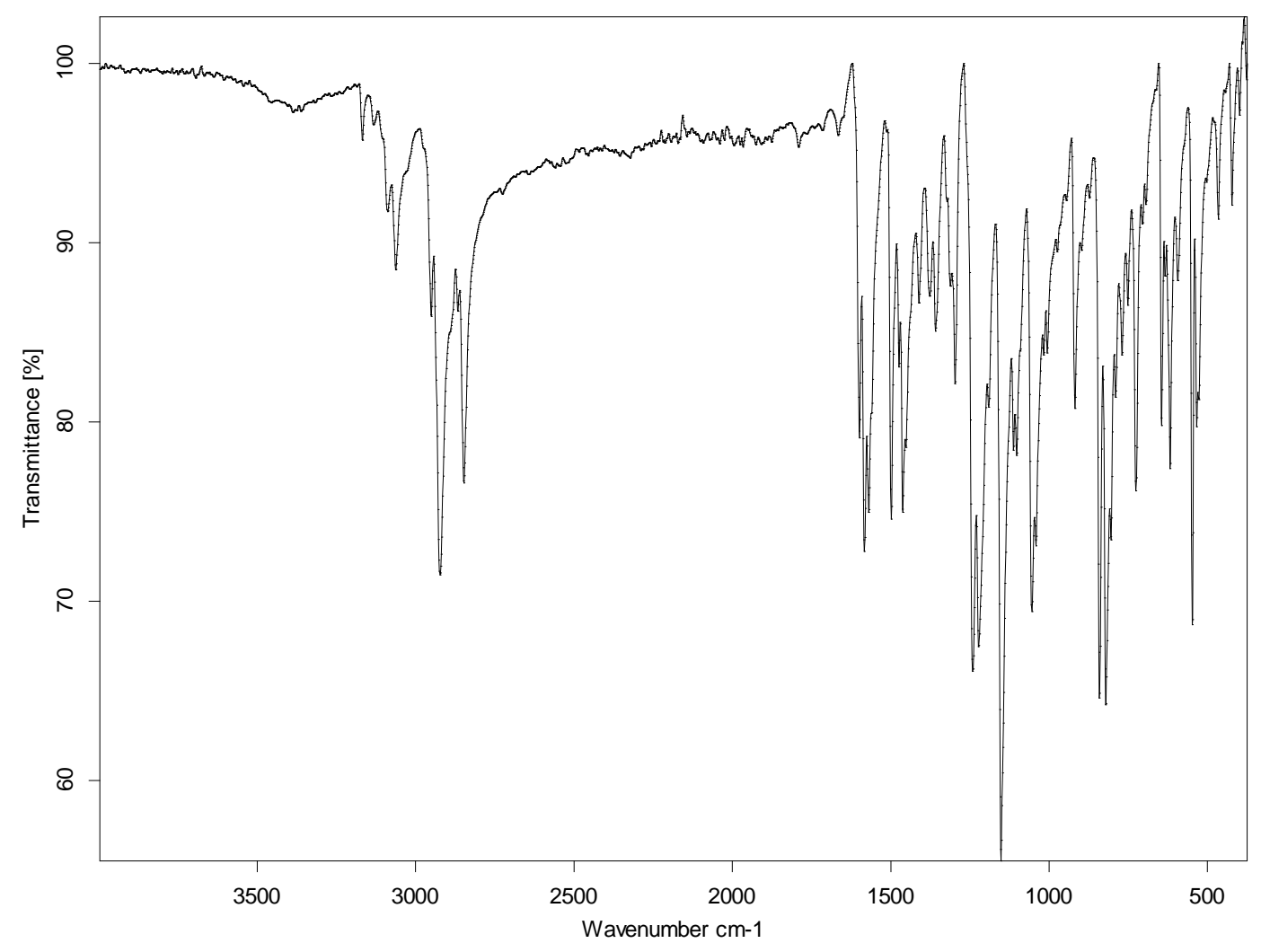

Figure S31: Infra-red spectrum of compound 1.

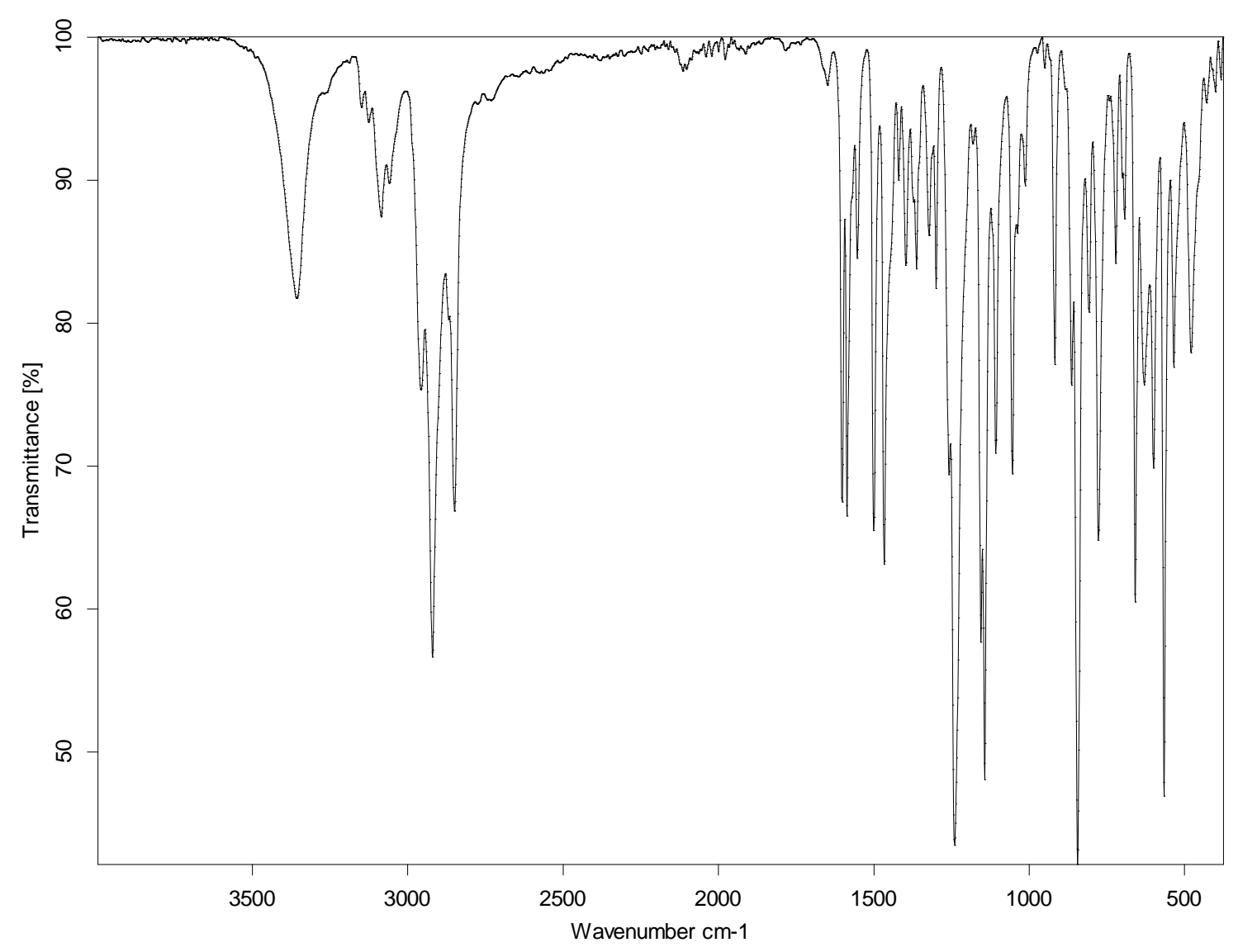

Figure S32: Infra-red spectrum of compound 2. 


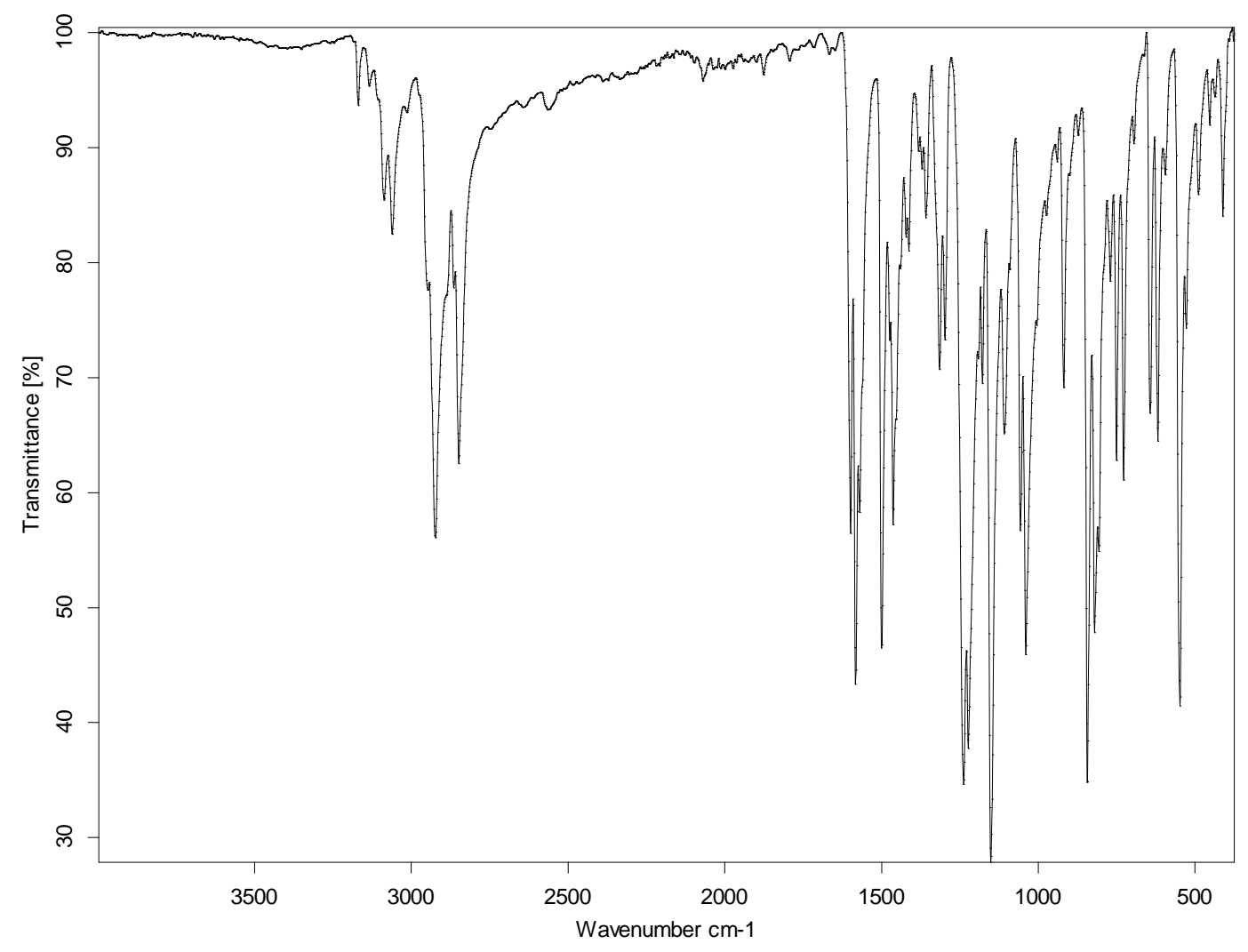

Figure S33: Infra-red spectrum of compound 3.

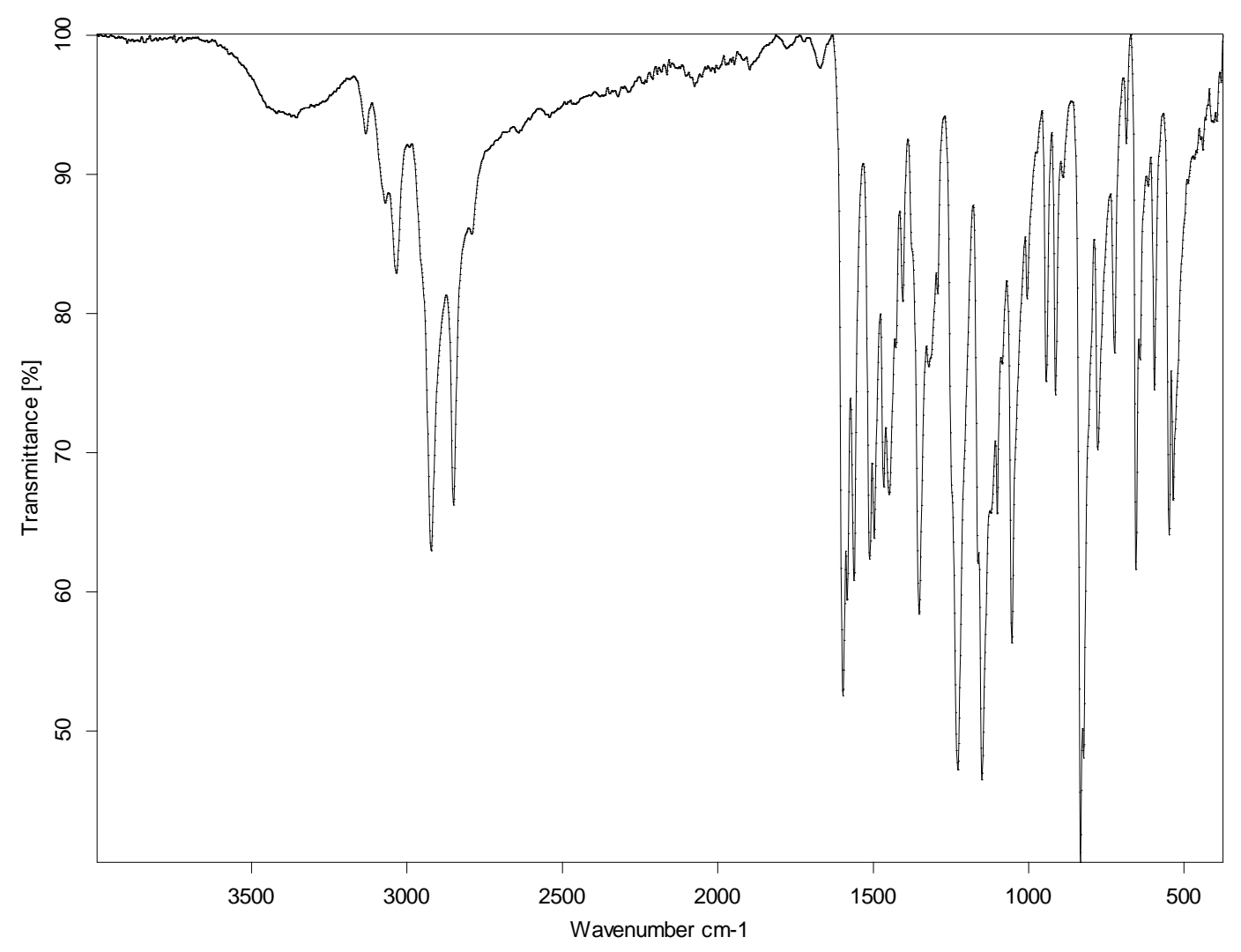

Figure S34: Infra-red spectrum of compound 4. 


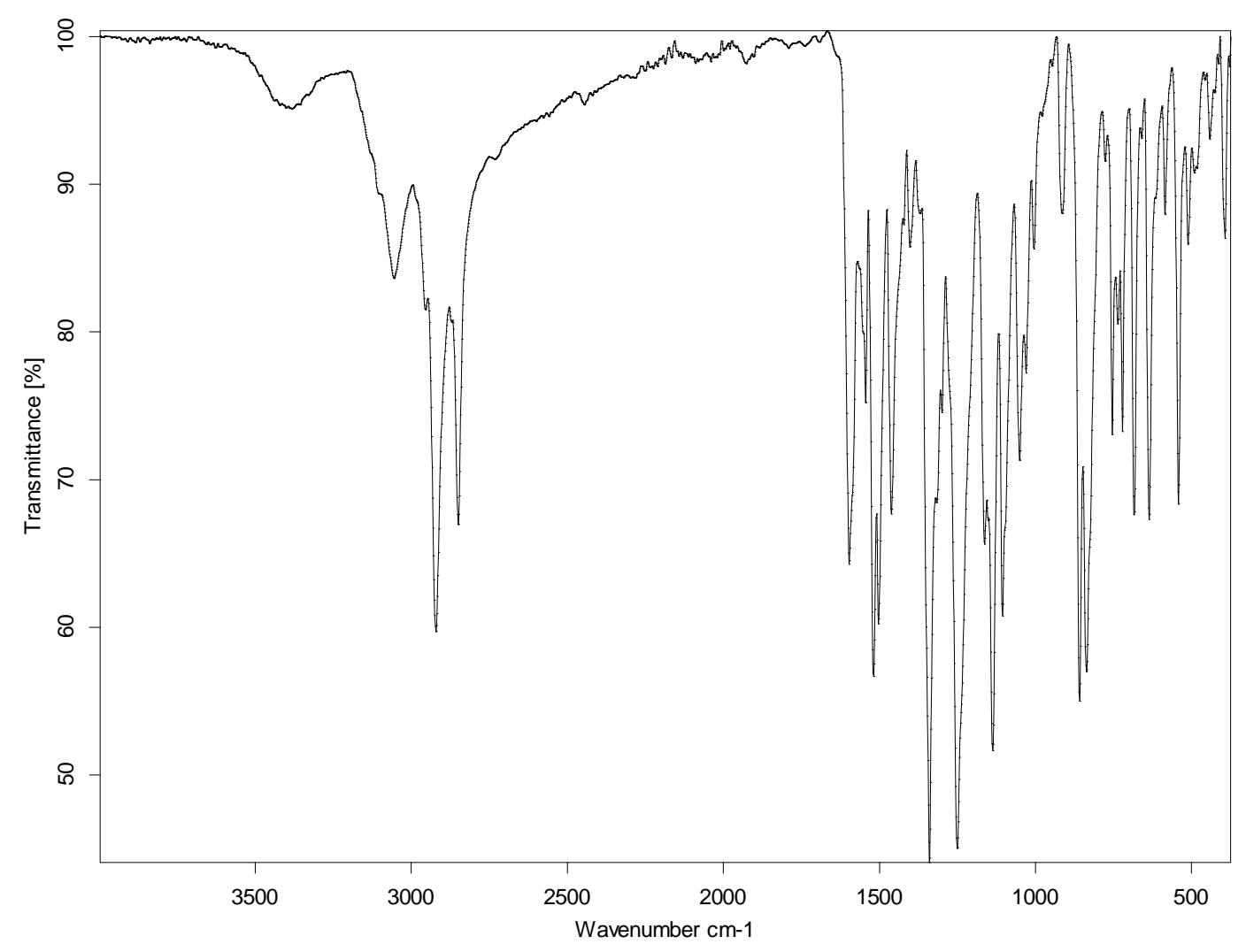

Figure S35: Infra-red spectrum of compound 5.

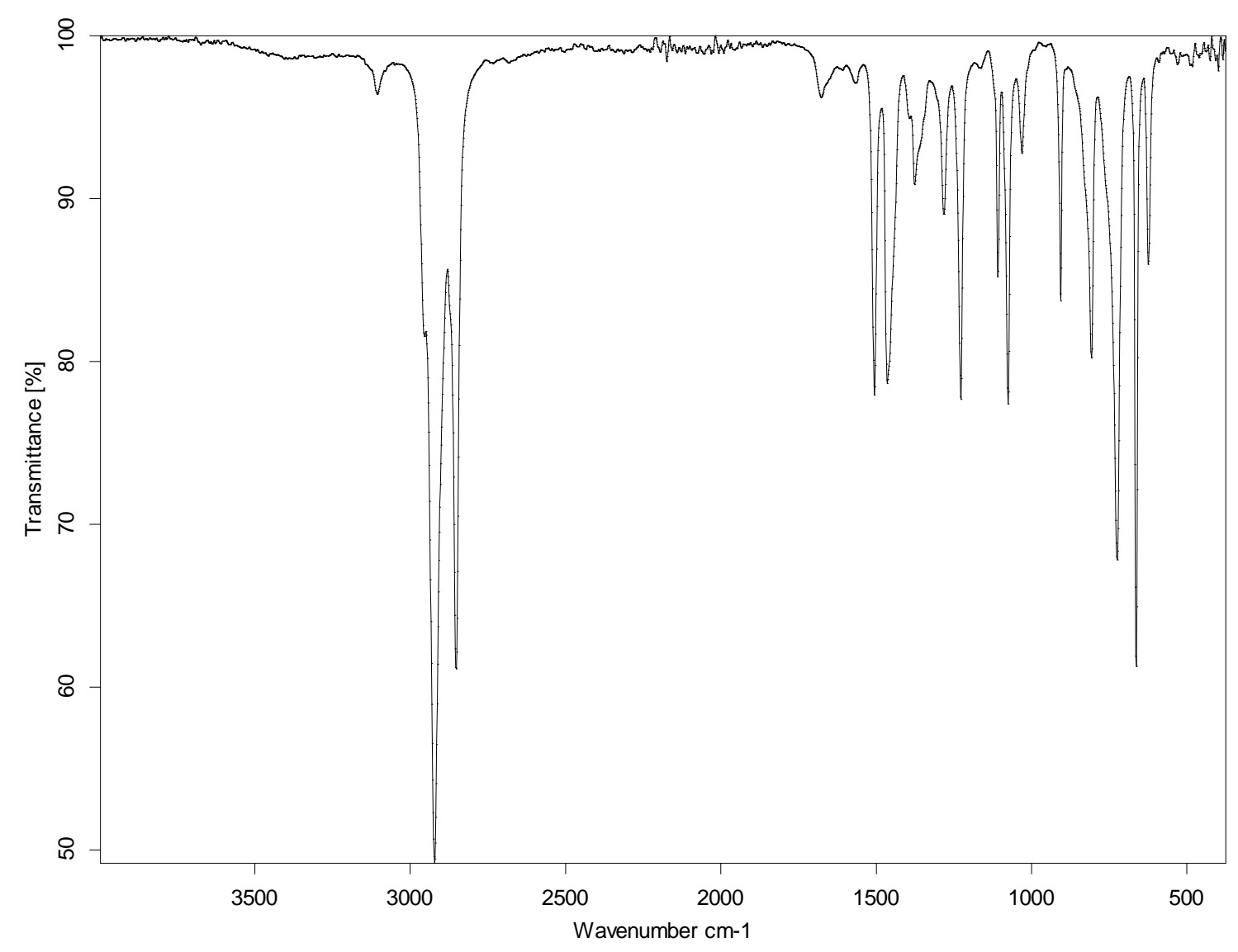

Figure S36: Infra-red spectrum of compound 6. 
III. Thermogravimetry Analysis

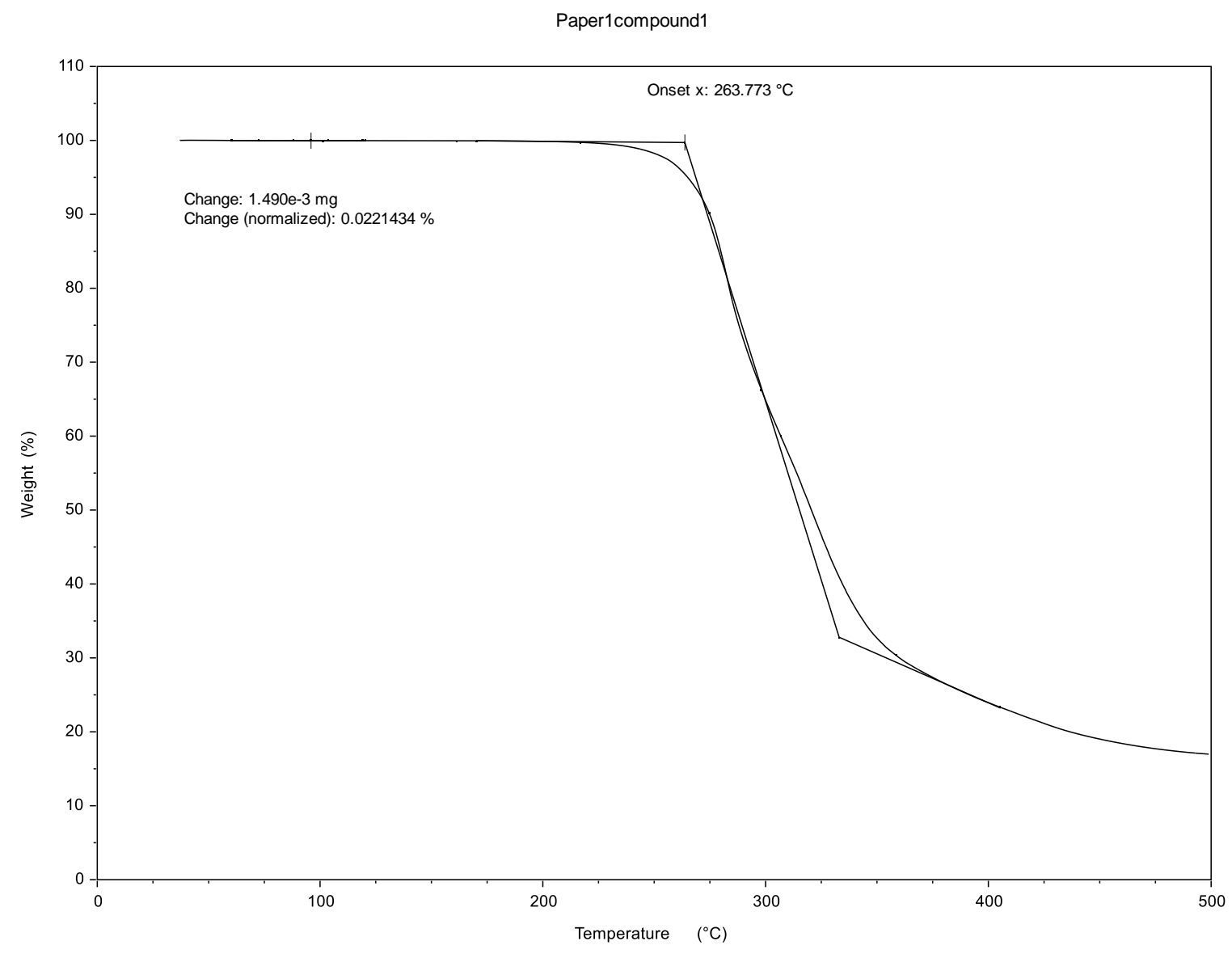

Figure S37: TGA thermogram of compound 1. 


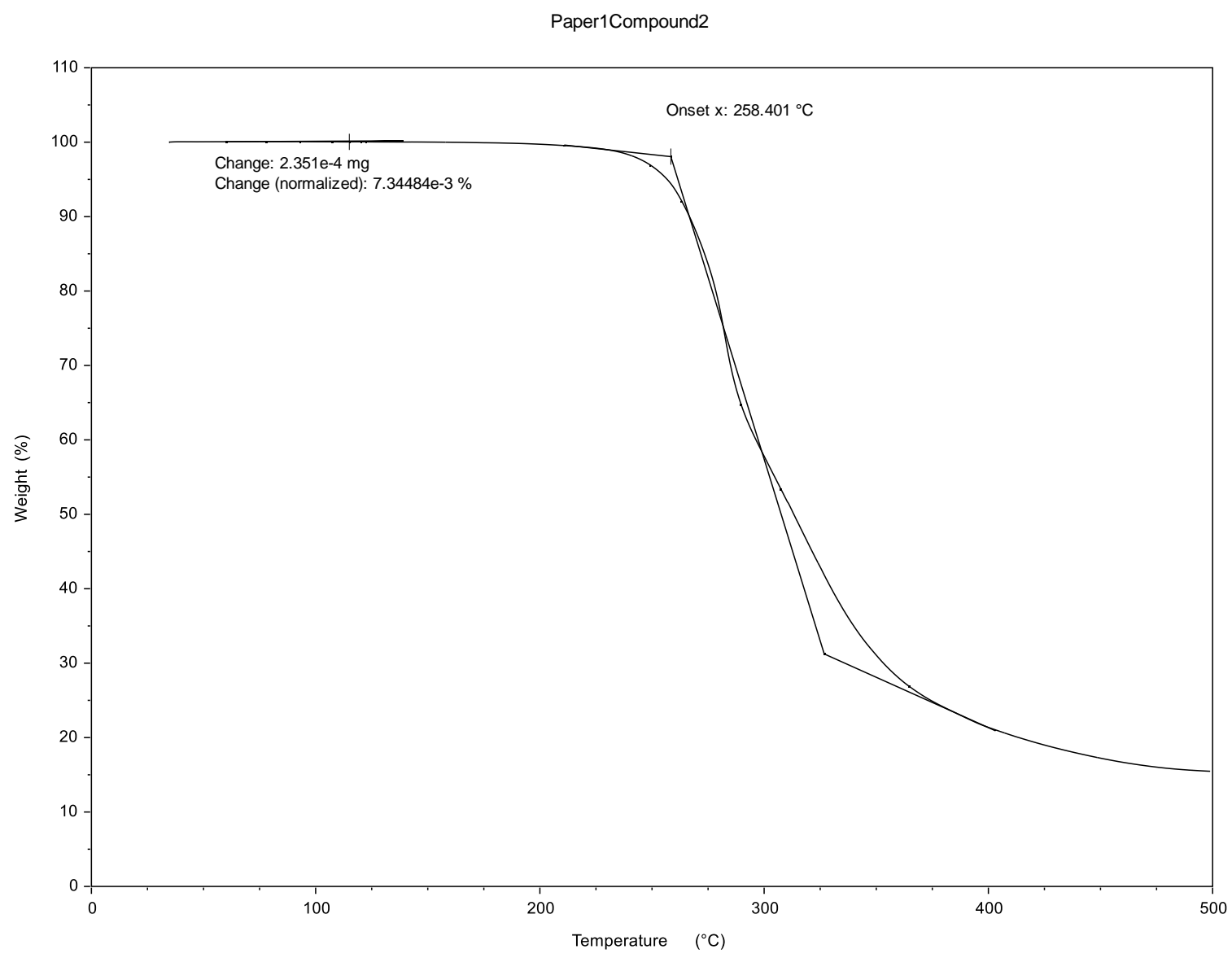

Figure S38: TGA thermogram of compound 2. 


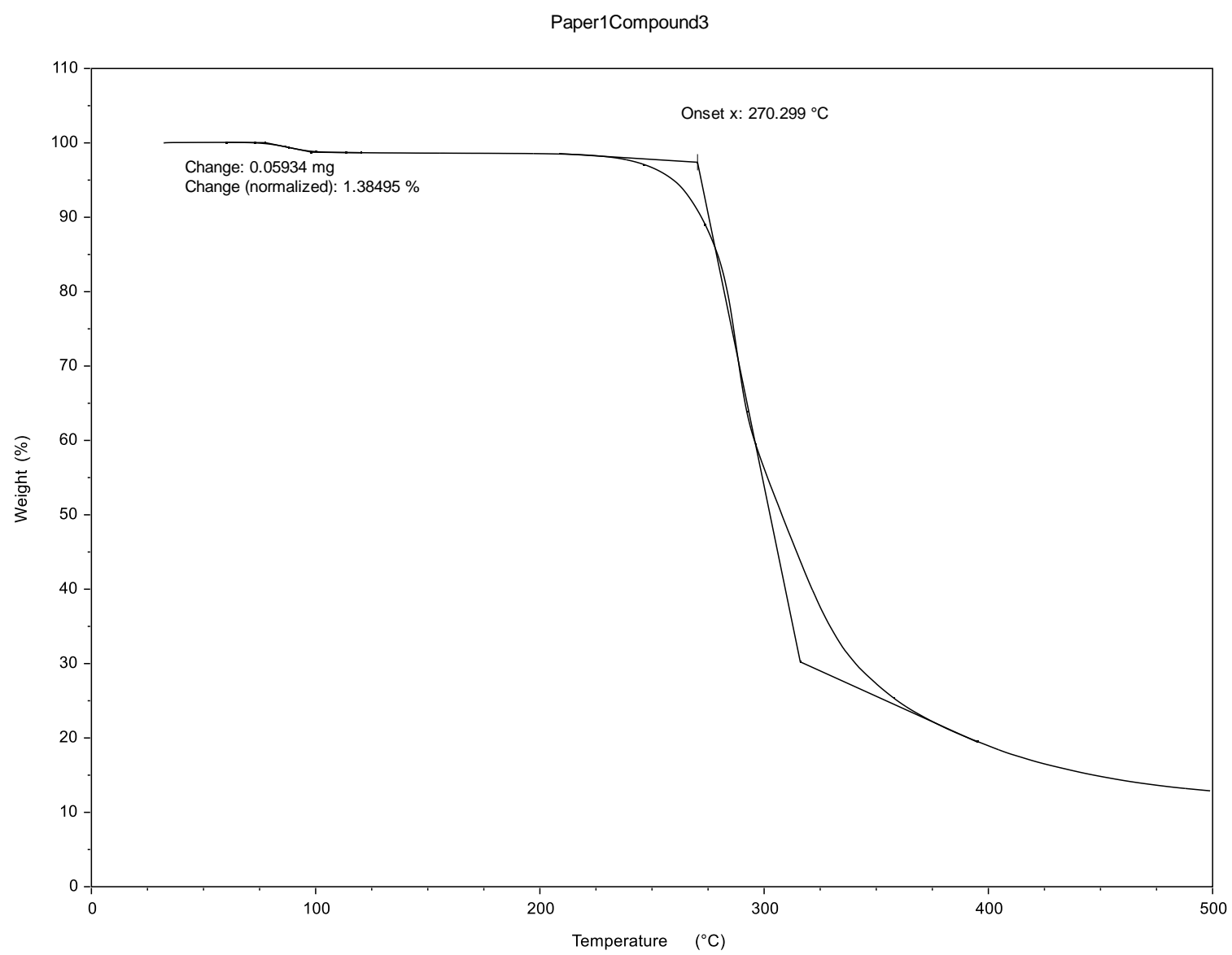

Figure S39: TGA thermogram of compound 3. 


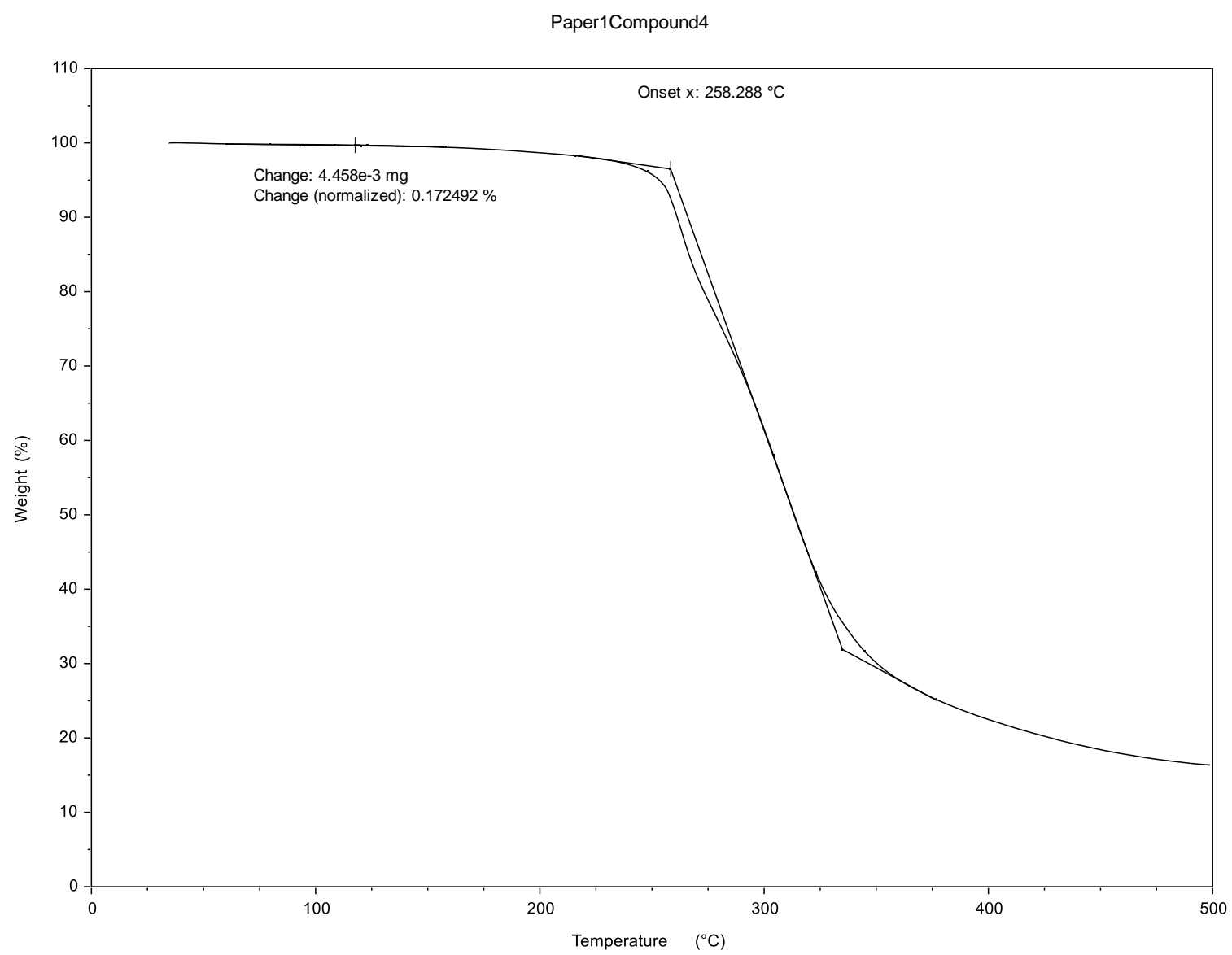

Figure S40: TGA thermogram of compound 4. 


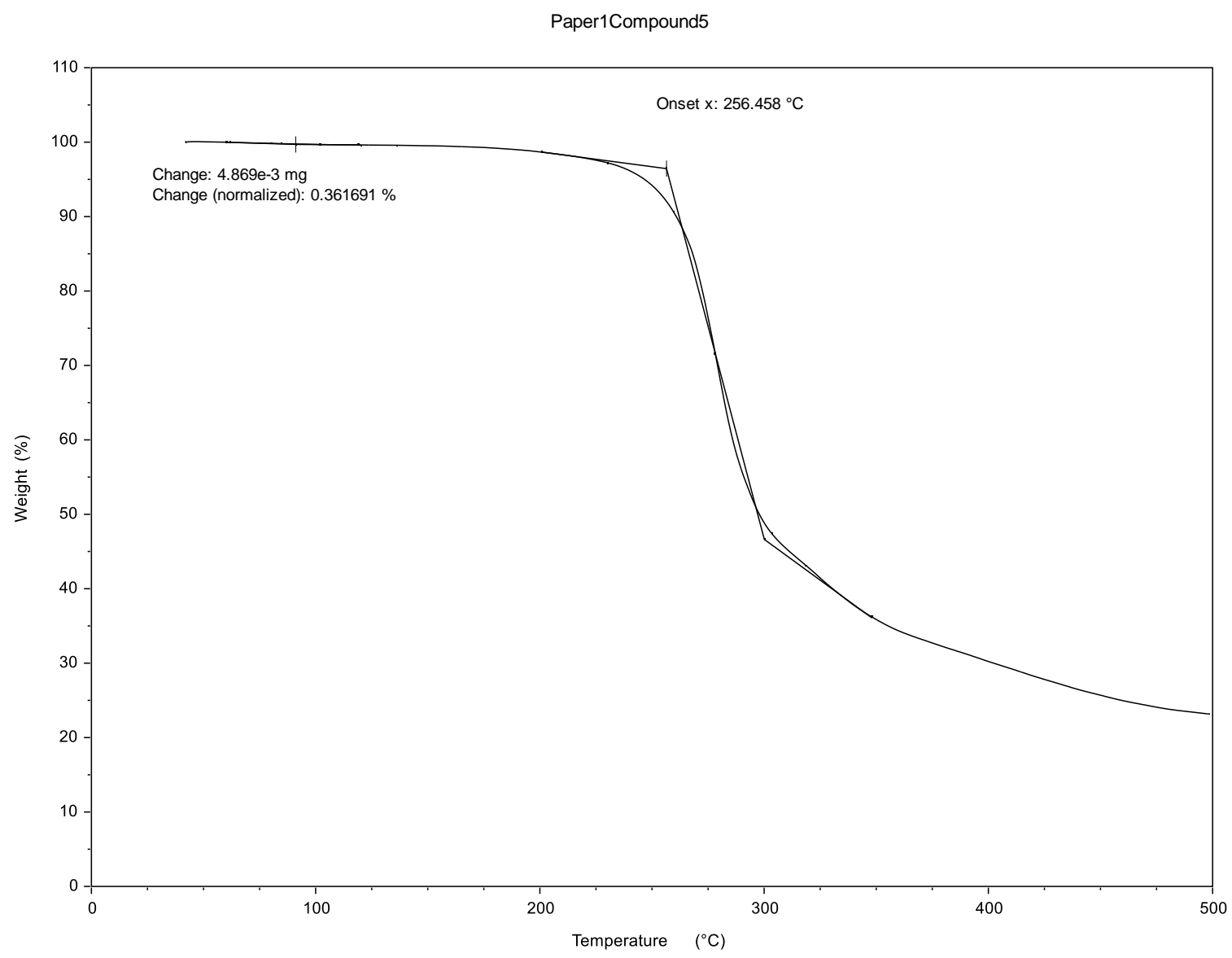

Figure S41: TGA thermogram of compound 5. 


\section{DFT Calculations}

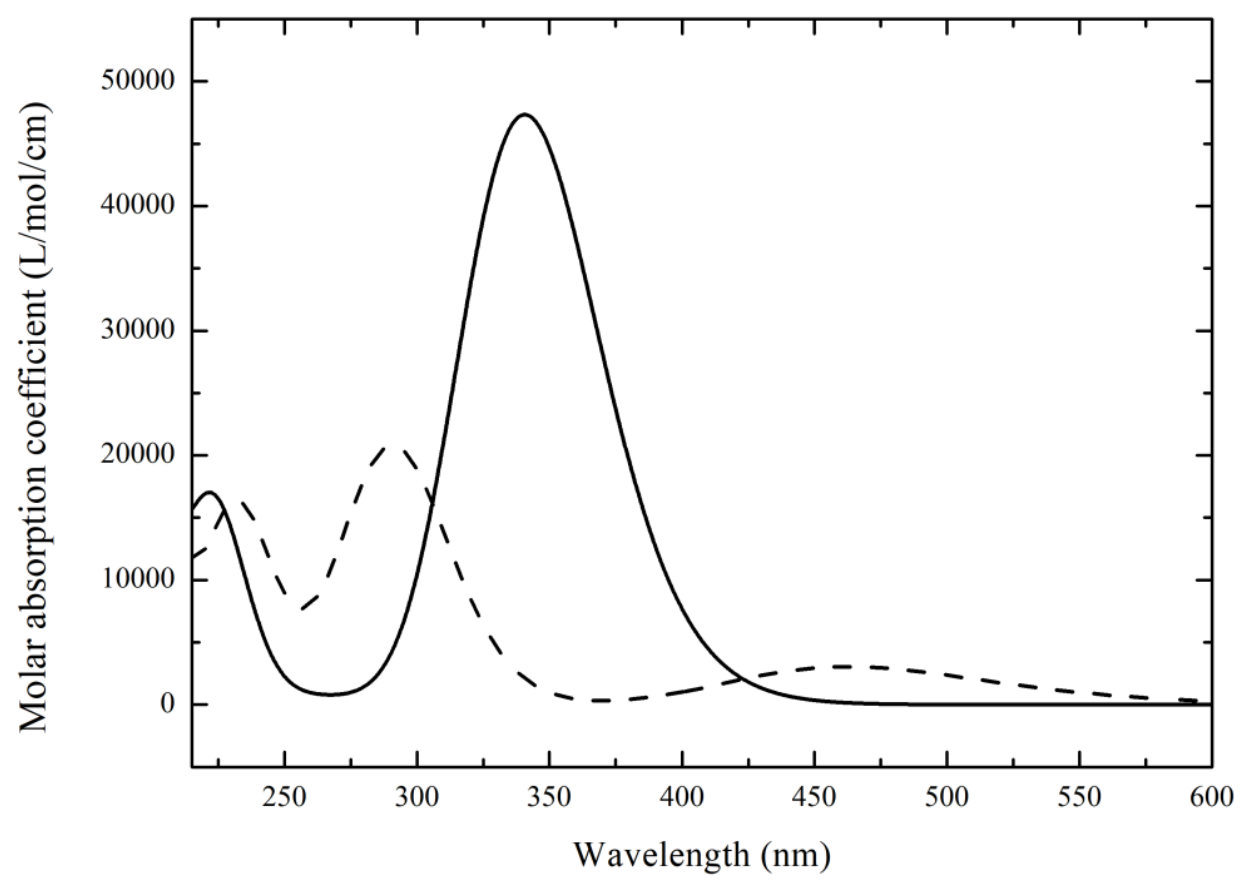

Figure S42: Simulated absorption spectra for trans (solid curve) and cis (dashed curve) isomers of compound 1. 


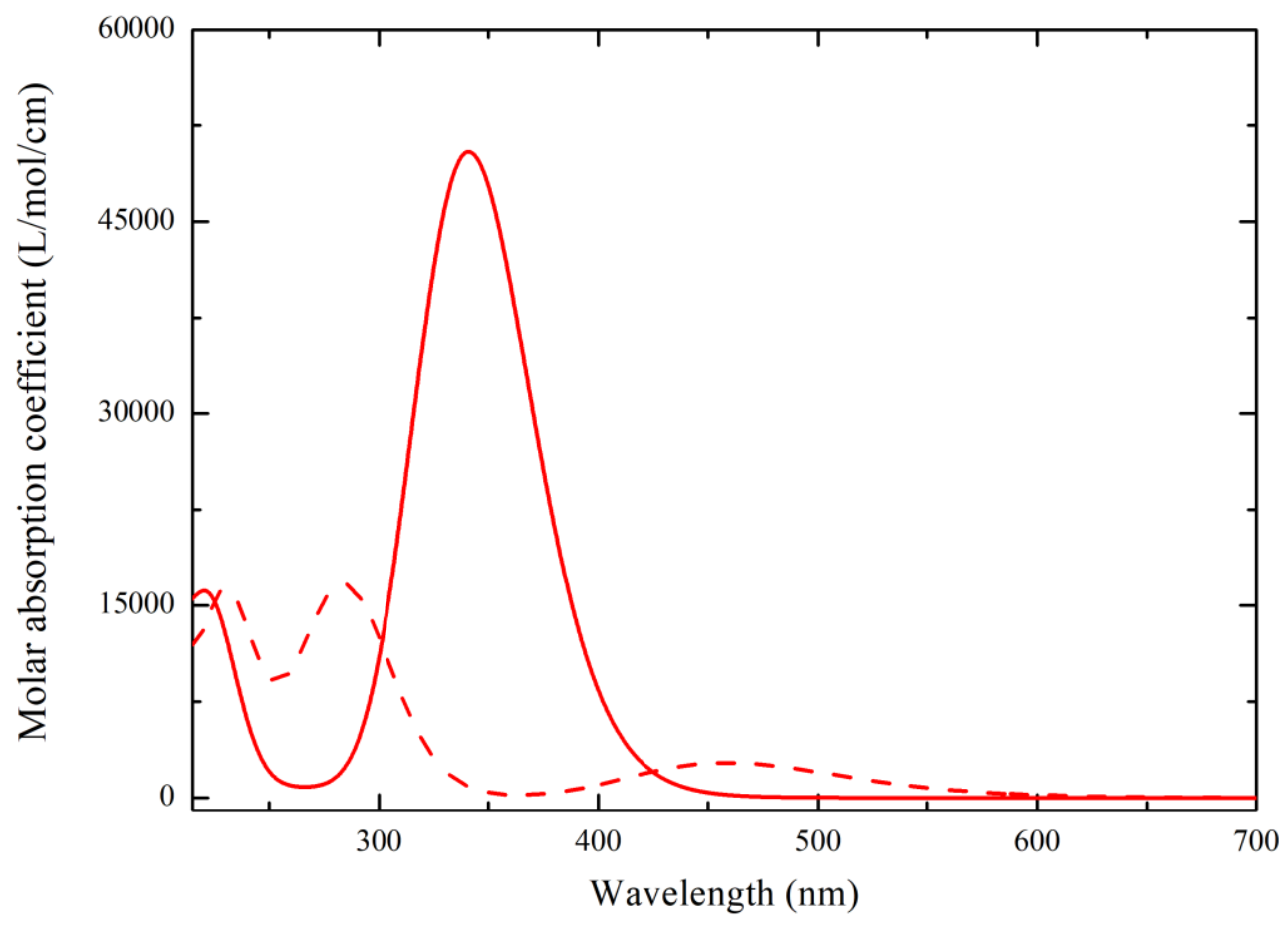

Figure S43: Simulated absorption spectra for trans (solid curve) and cis (dashed curve) isomers of compound 2.

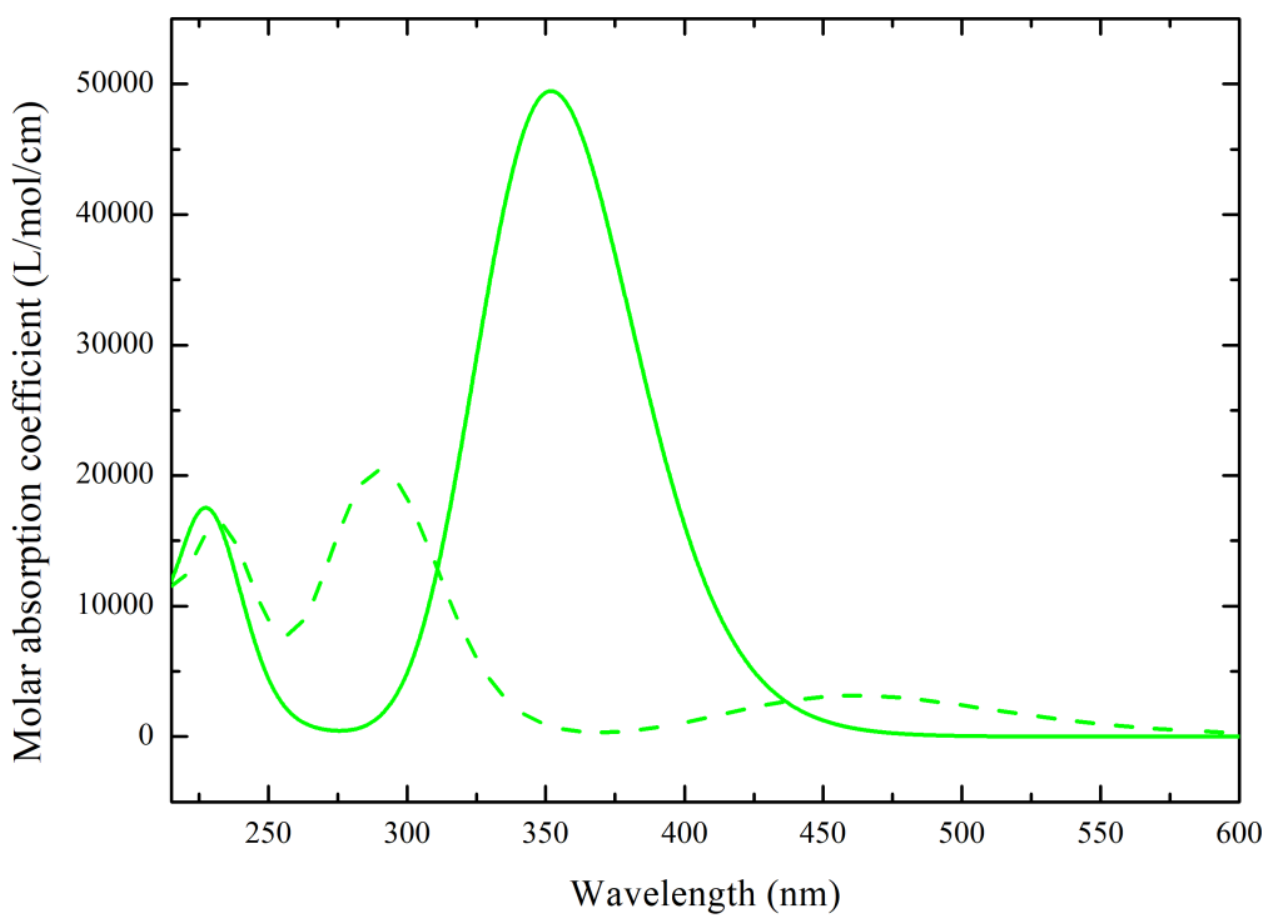

Figure S44: Simulated absorption spectra for trans (solid curve) and cis (dashed curve) isomers of compound $\mathbf{3}$. 


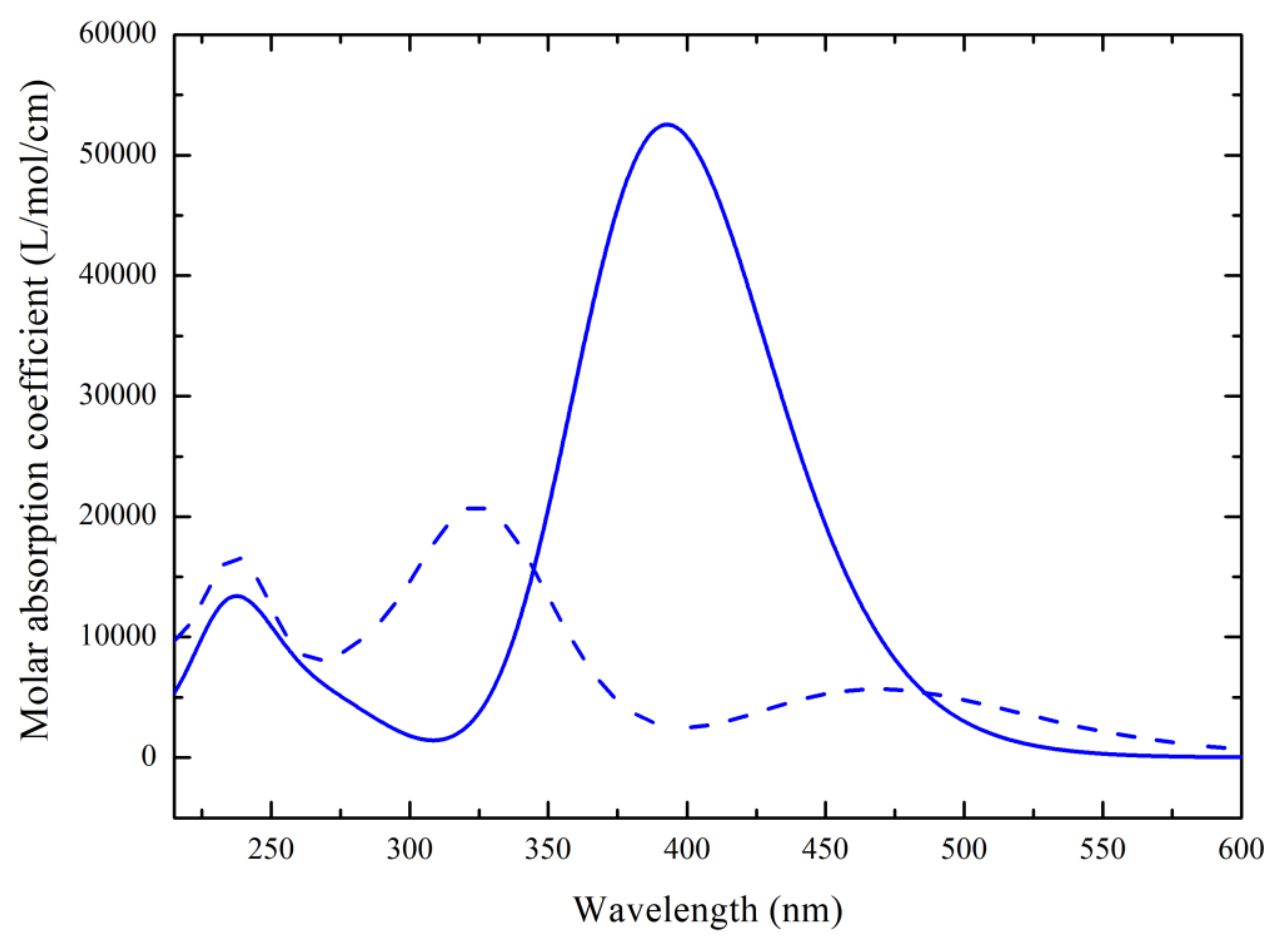

Figure S45: Simulated absorption spectra for trans (solid curve) and cis (dashed curve) isomers of compound 4.

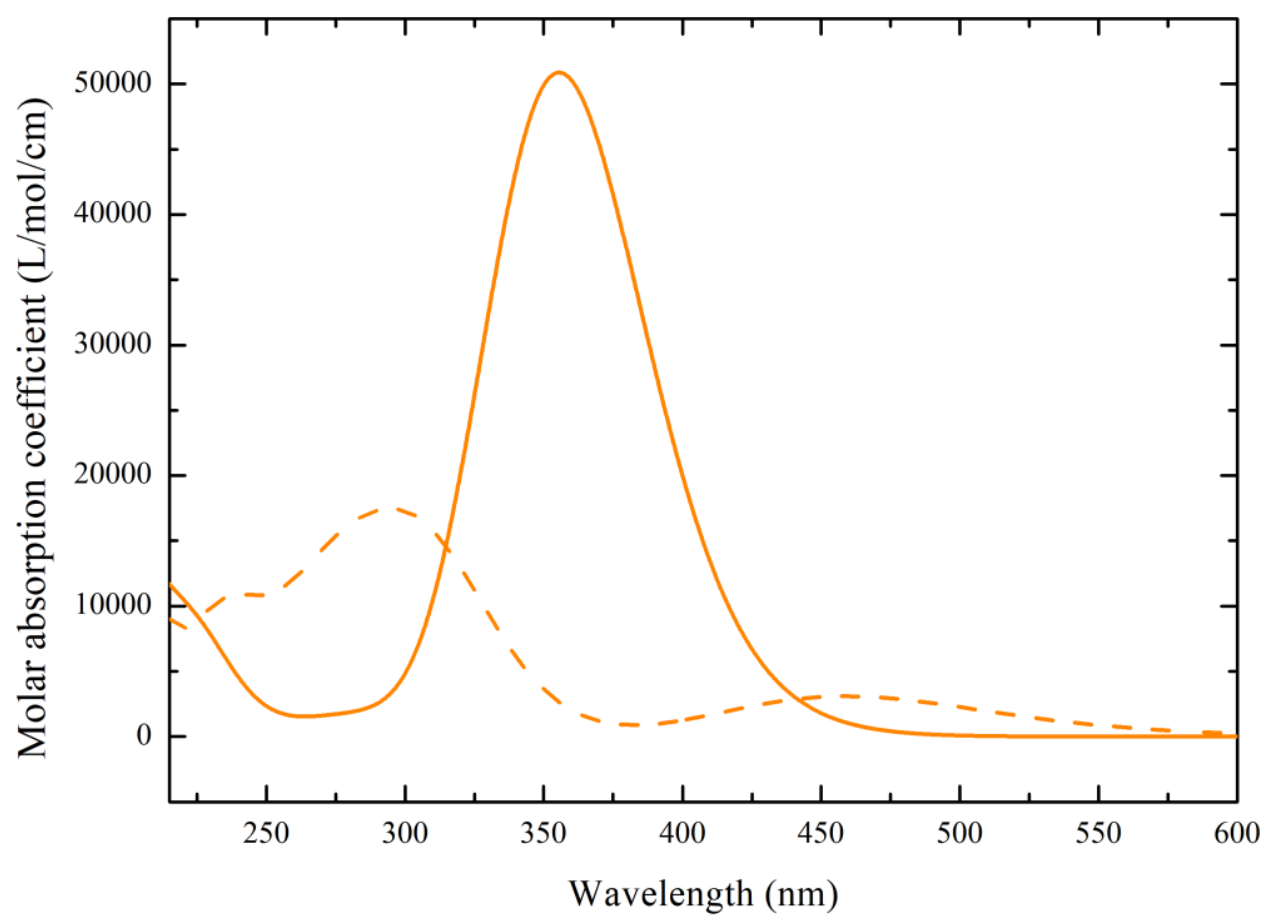

Figure S46: Simulated absorption spectra for trans (solid curve) and cis (dashed curve) isomers of compound $\mathbf{5}$. 
Table S1: 3D molecular structures and molecular orbitals of trans and cis isomers of compound 1.

\section{LUMO+2}
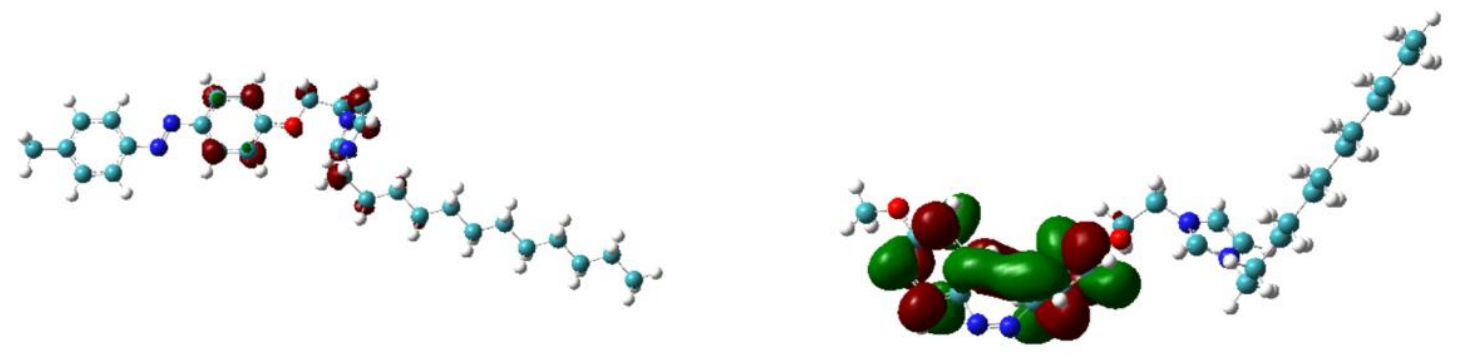

LUMO+1
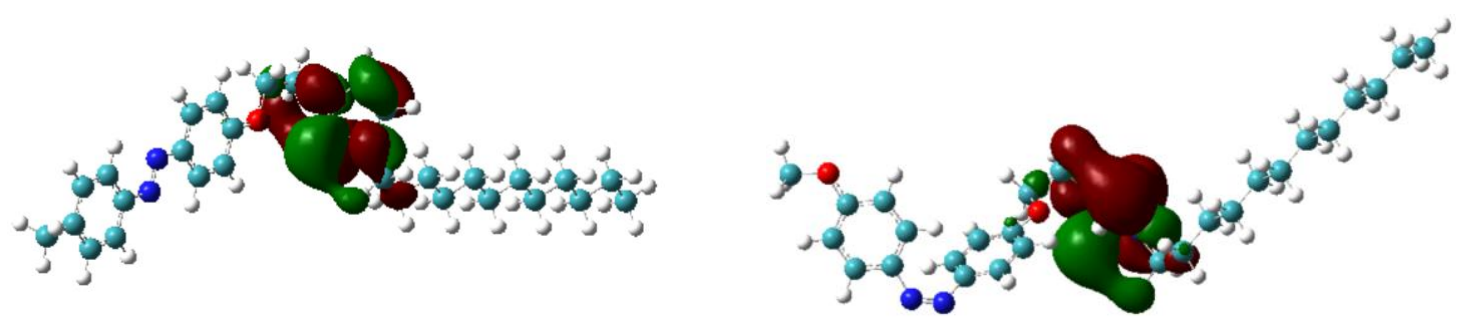

LUMO
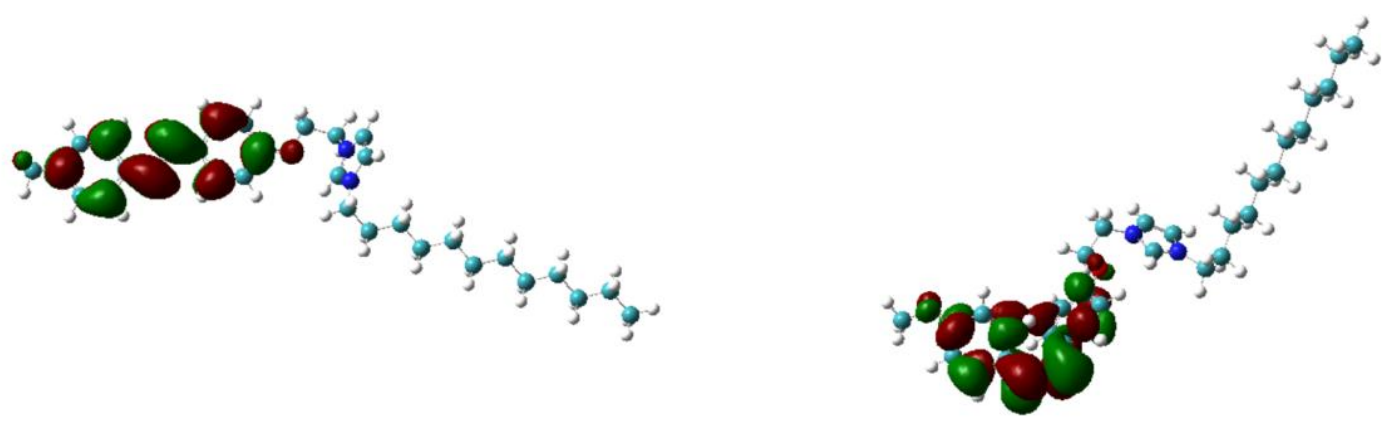

HOMO
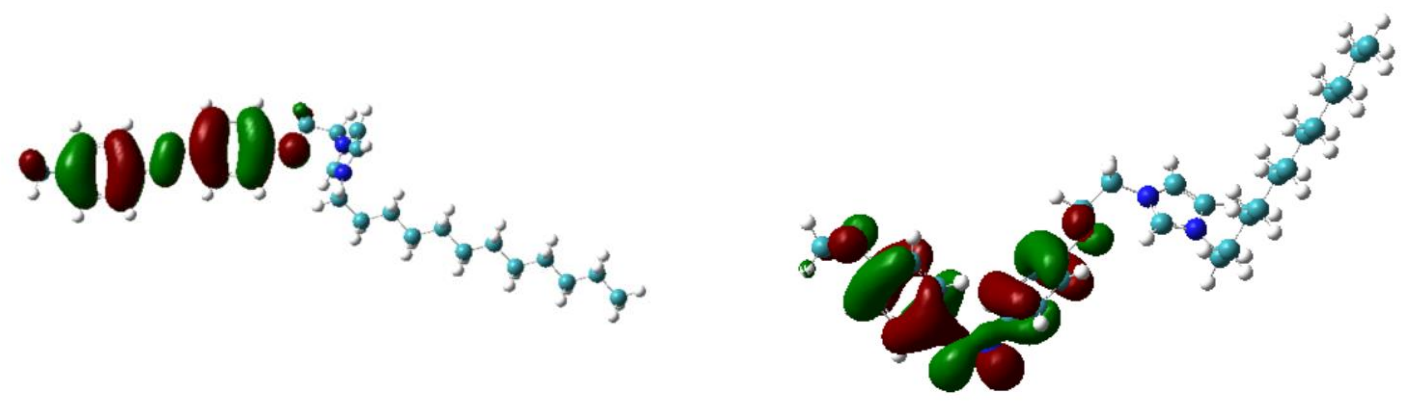

HOMO-1 


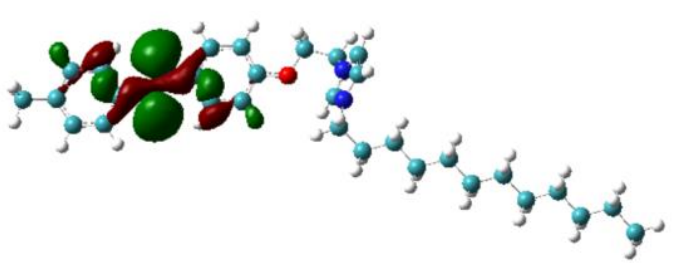

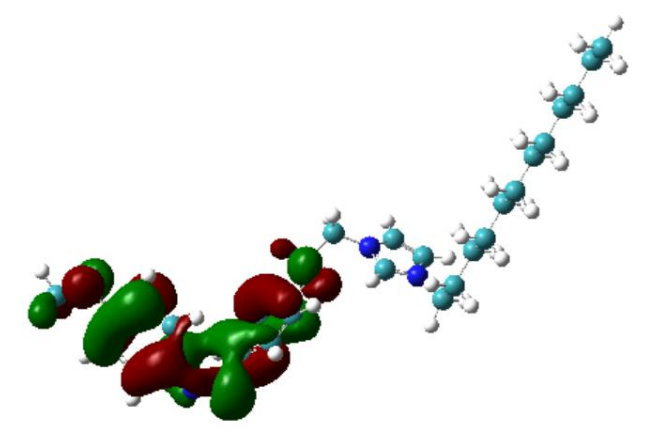

HOMO-2
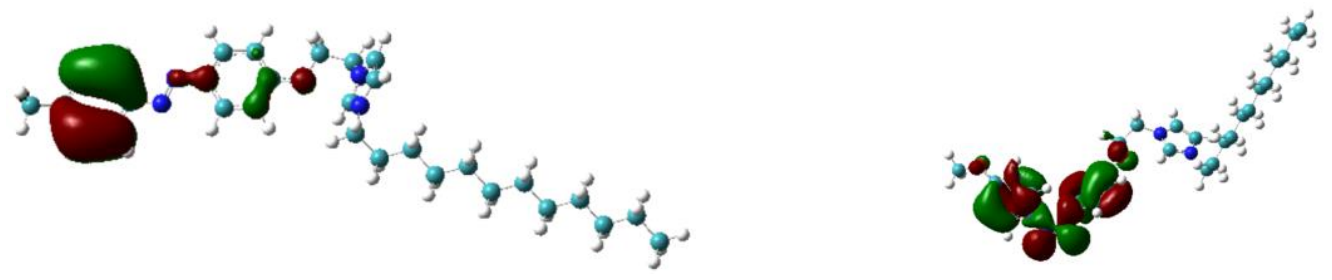
Table S2: 3D molecular structures and molecular orbitals of trans and cis isomers of compound 2.

LUMO+2
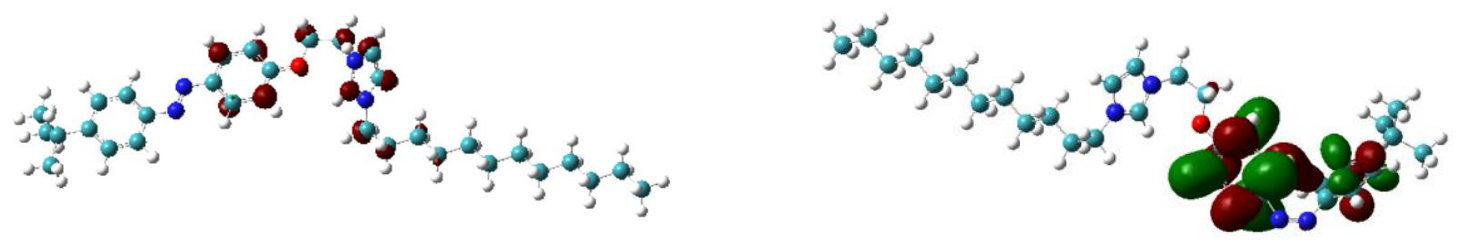

LUMO+1
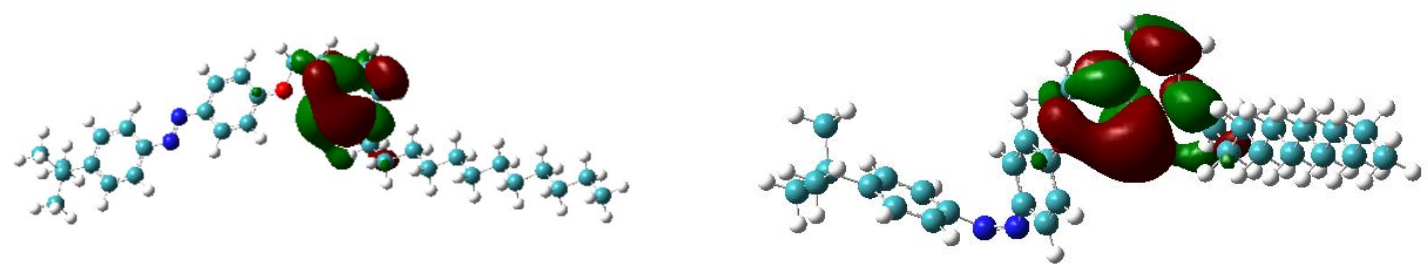

LUMO
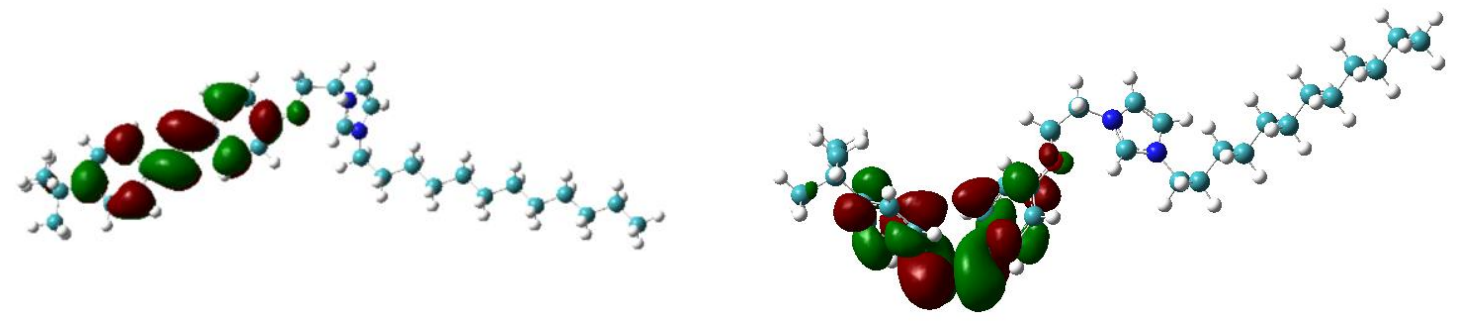

HOMO
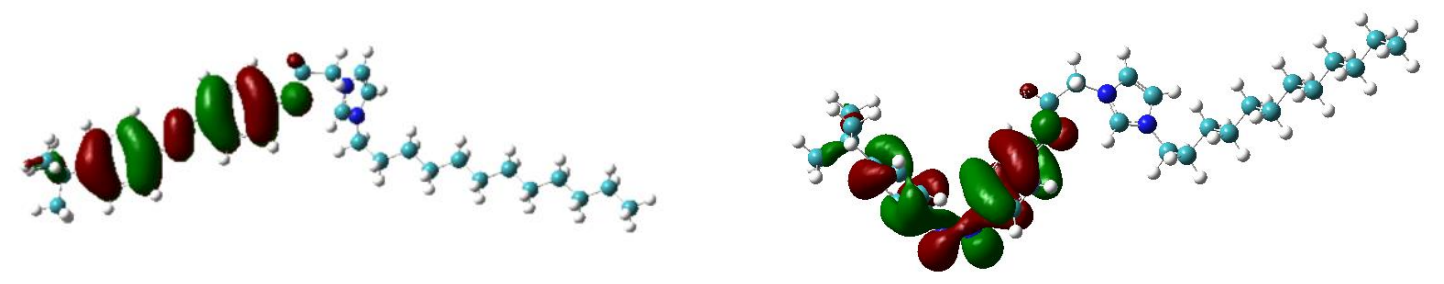

HOMO-1
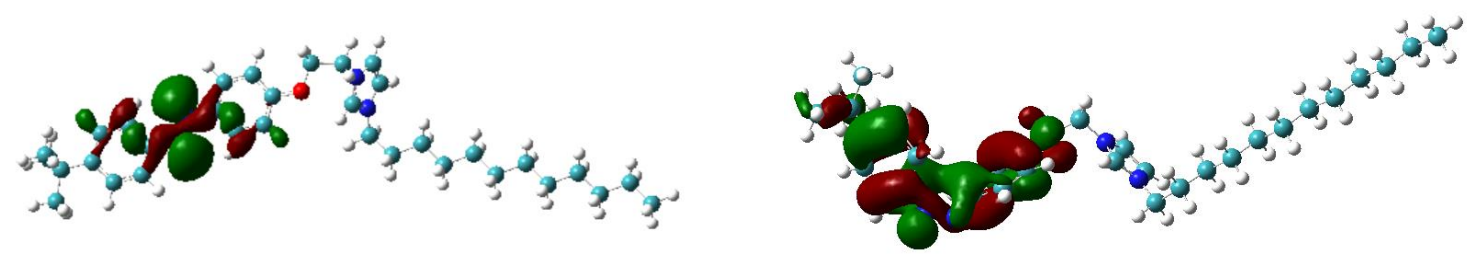

HOMO-2 


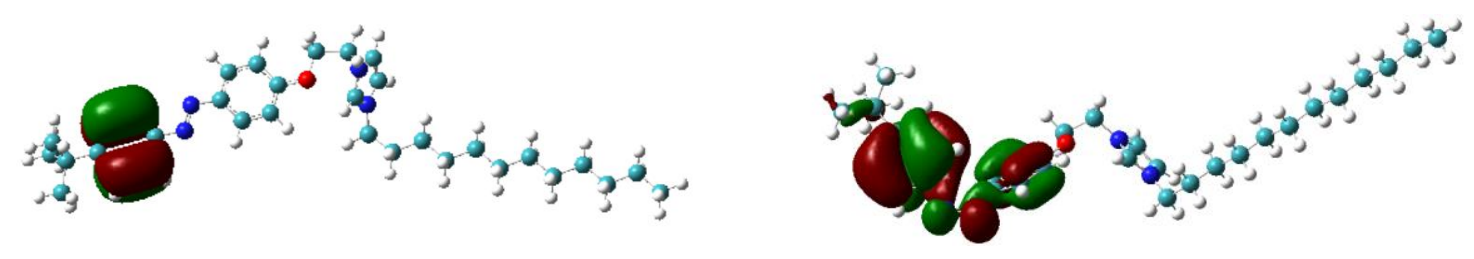

HOMO-3

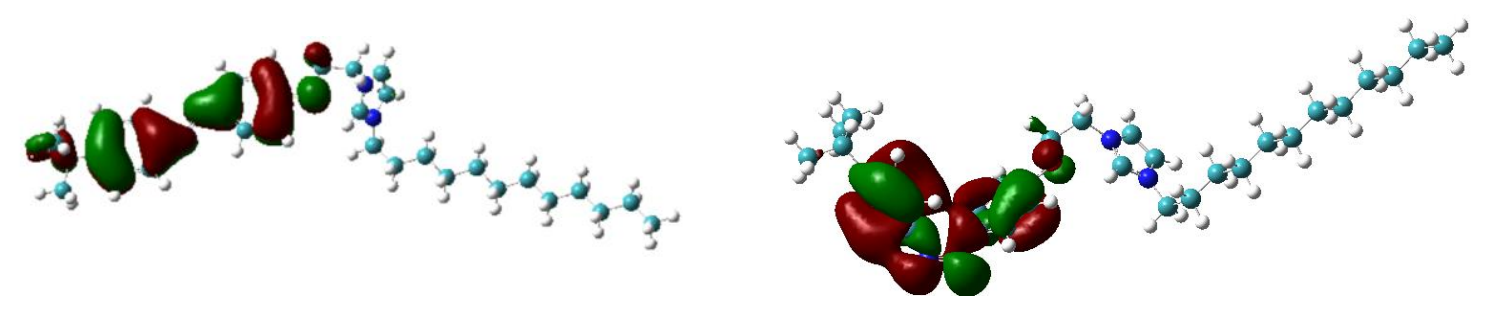


Table S3: 3D molecular structures and molecular orbitals of trans and cis isomers of compound 3.

\section{LUMO+2}

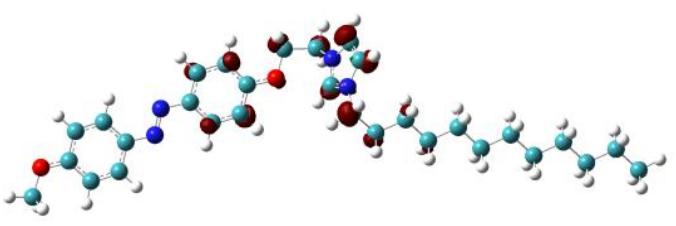

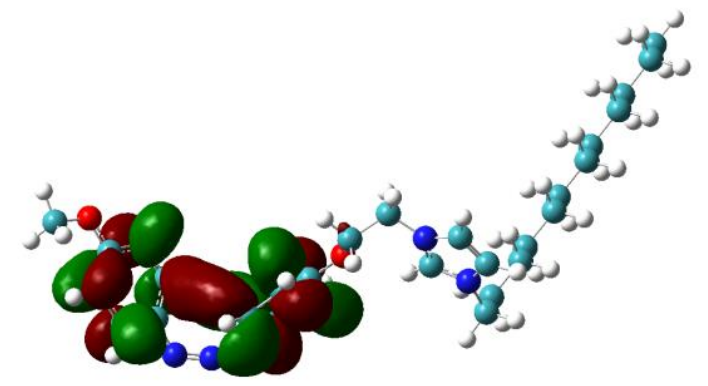

LUMO+1
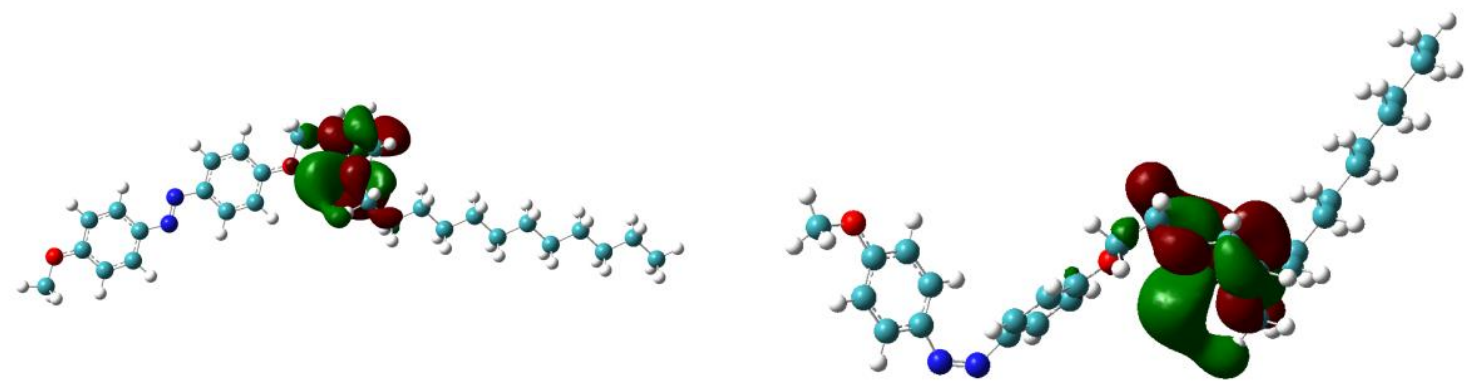

LUMO
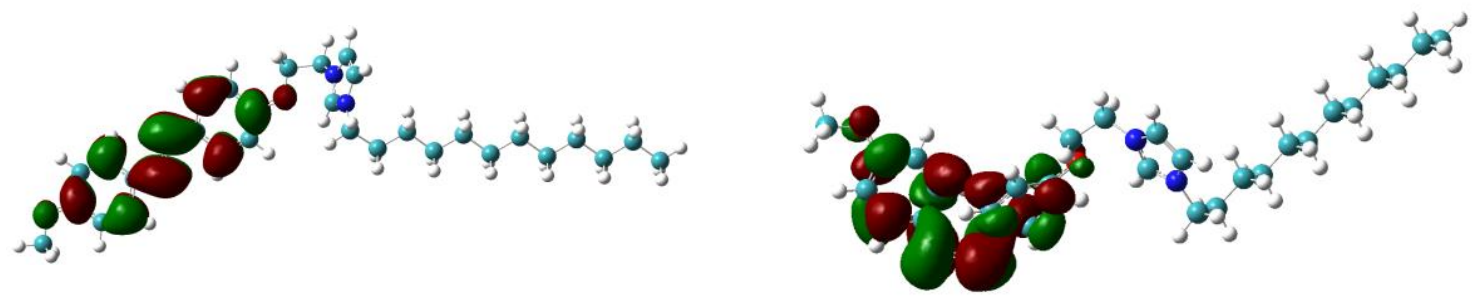

$\mathrm{HOMO}$
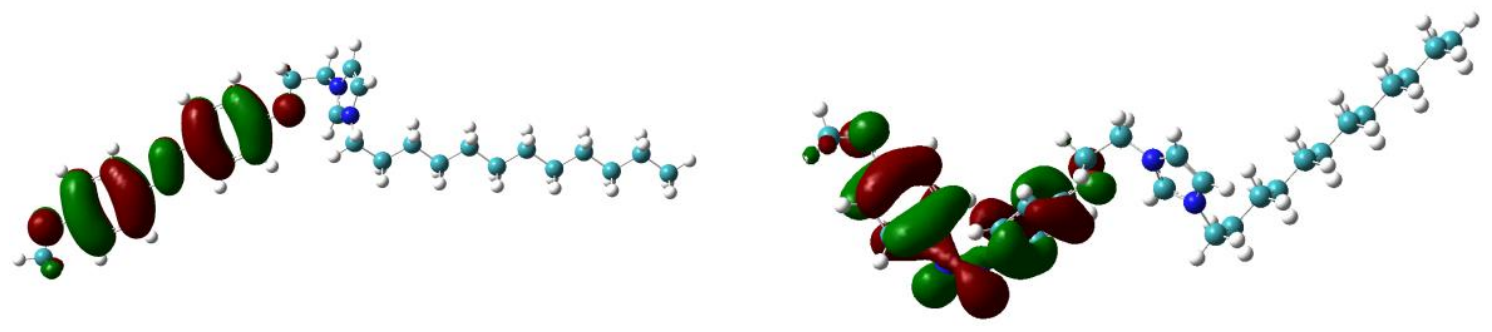

HOMO-1 


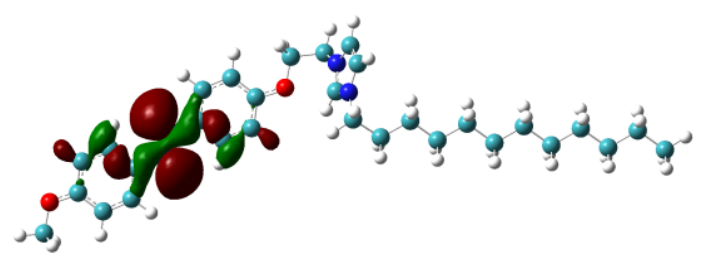

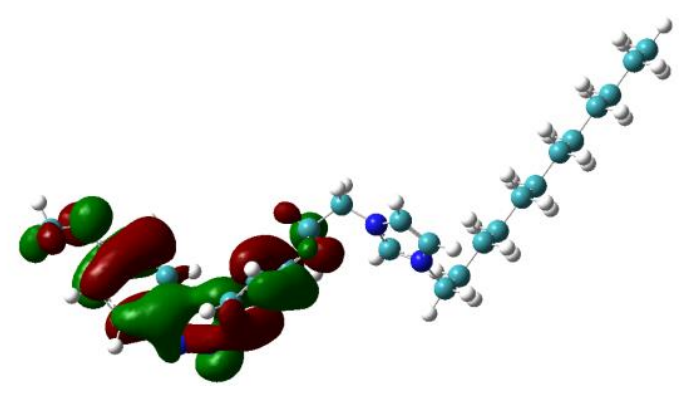

HOMO-2
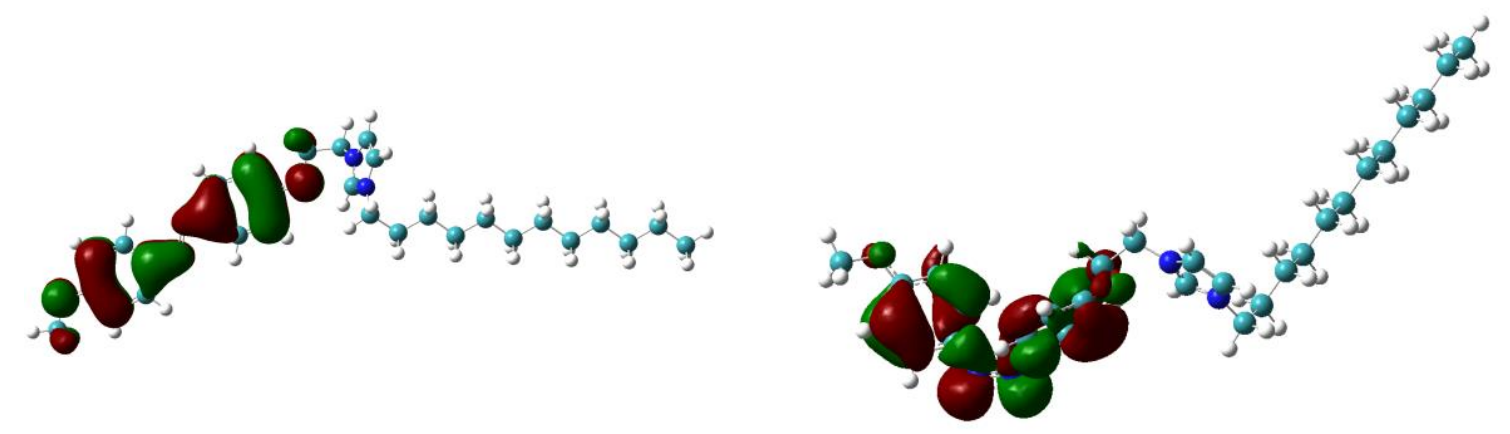
Table S4: 3D molecular structures and molecular orbitals of trans and cis isomers of compound 4.

\section{LUMO+2}

a

LUMO+1

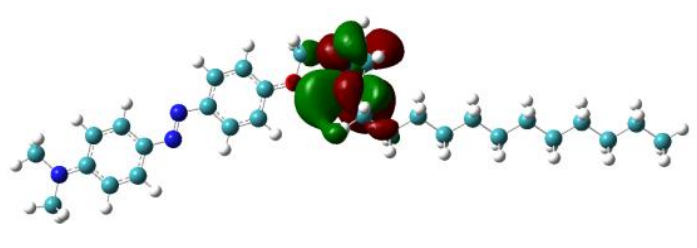

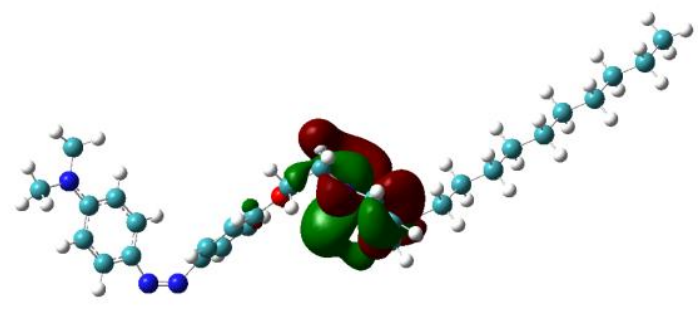

LUMO
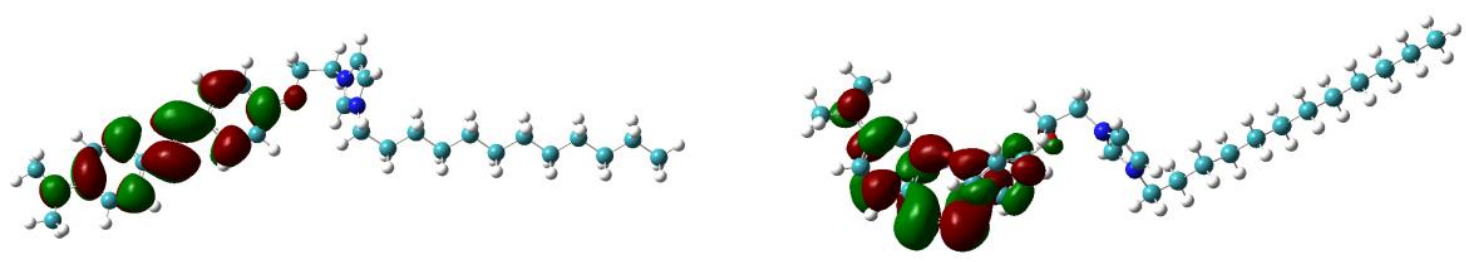

$\mathrm{HOMO}$
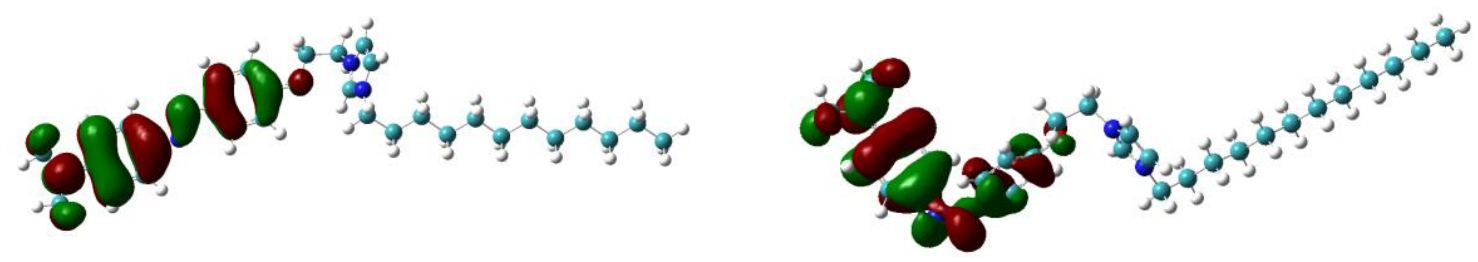

HOMO-1
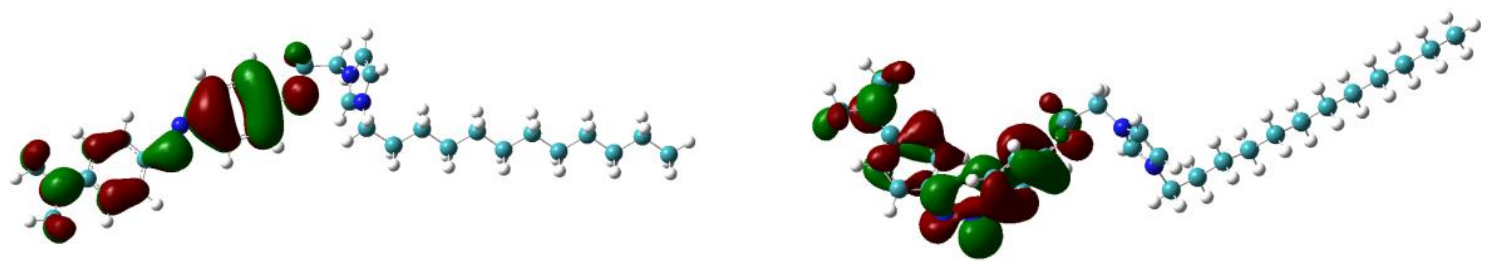

HOMO-2 
$\log ^{0,0}$ 
Table S5: 3D molecular structures and molecular orbitals of trans and cis isomers of compound 5.

LUMO+2
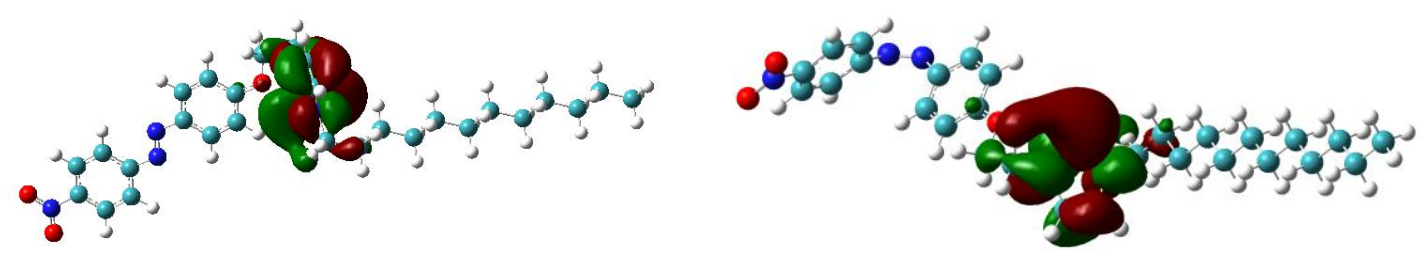

LUMO+1
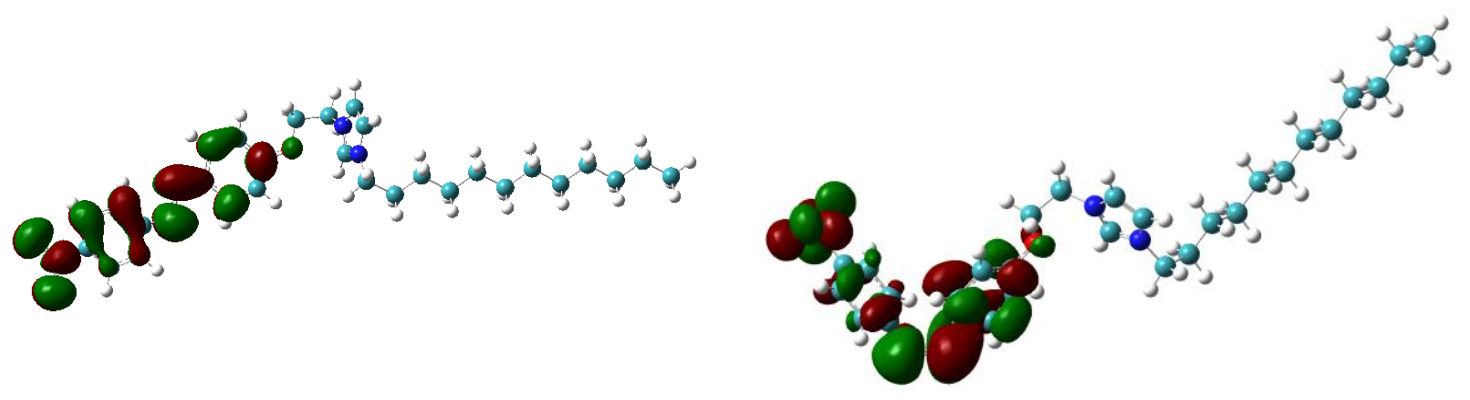

LUMO
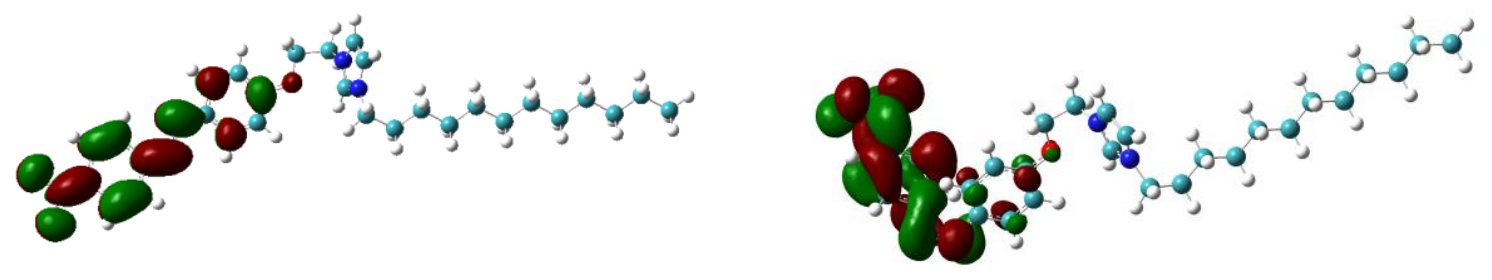

$\mathrm{HOMO}$
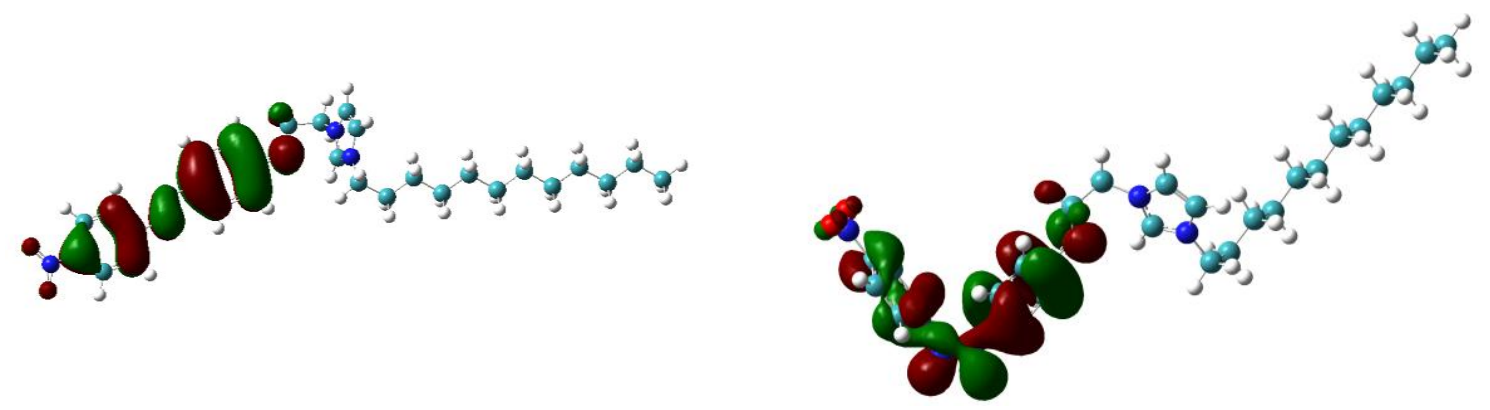

HOMO-1 

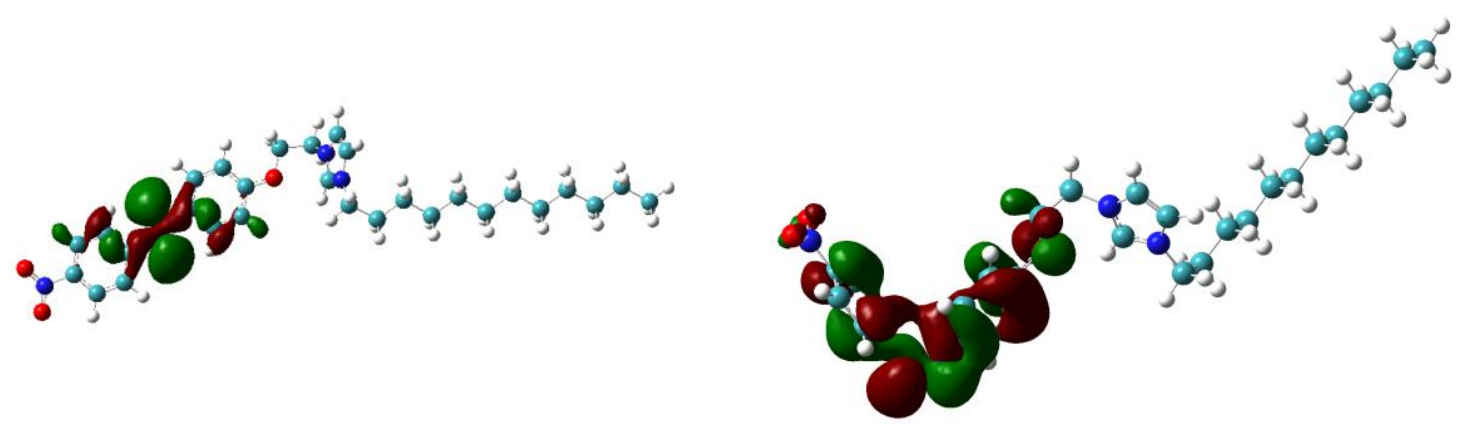

HOMO-2
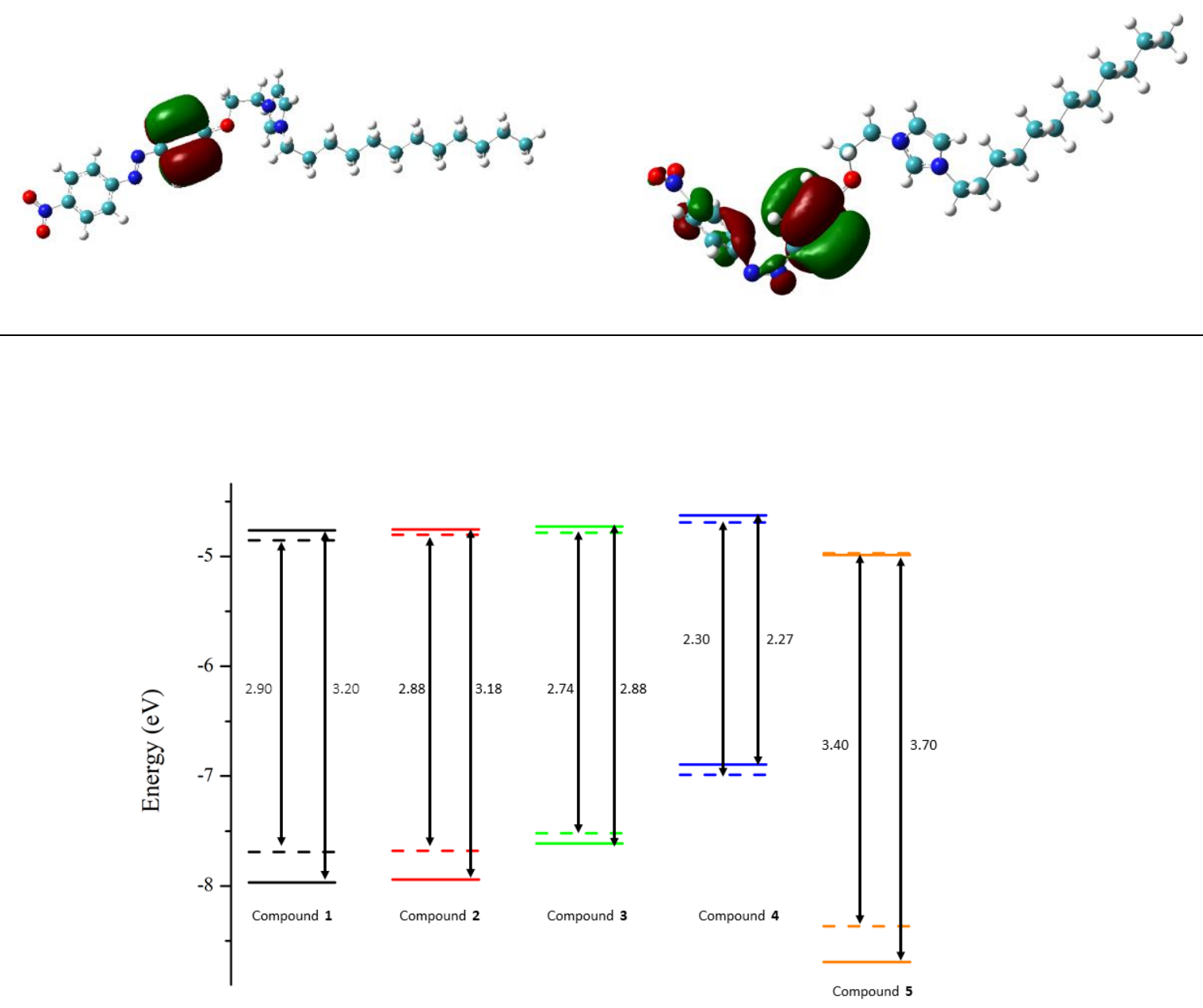

Figure S47: Molecular orbital energy level diagrams of trans (solid line) and cis (dashed line) isomers of compounds 1-5. 